\title{
SMALL SCALE VERTICAL AXIS WIND TURBINE
}

by

Sahishnukumar Shah

B.Tech Electrical \& Electronics Engineering, 2011 CUSAT

\author{
A project \\ presented to Ryerson University \\ in partial fulfillment of the \\ requirements for the degree of \\ Master of Engineering \\ in the program of
}

Electrical \& Computer Engineering

Toronto, Ontario, Canada, 2015

C)Sahishnukumar Shah 2015 


\begin{abstract}
AUTHOR'S DECLARATION
I hereby declare that I am the sole author of this project. This is a true copy of the project, including any required final revisions, as accepted by my examiners.

I authorize Ryerson University to lend this project to other institutions or individuals for the purpose of scholarly research.

I further authorize Ryerson University to reproduce this project by photocopying or by other means, in total or in part, at the request of other institutions or individuals for the purpose of scholarly research.
\end{abstract}

I understand that my project may be made electronically available to the public. 


\title{
SMALL SCALE VERTICAL AXIS WIND TURBINE
}

Sahishnukumar Shah, M.Eng in Electrical and Computer Engineering, Ryerson University - 2015

\begin{abstract}
The small-scale vertical axis wind turbine is designed and modeled in this project, considering all aspects of wind turbine such as Blade design, stator design, rotor design and converter system design. Electric Power has become a prime necessity for any country for economic development. The conventional fuel sources for power generation are depleting fast. The favorable alternatives are renewable energy sources. Although more invention has to be carried out in the field of renewable energy sources, every little effort in this direction may provide a solution to reach most economical power generation point. Hence the same topic was selected for Masters Project.
\end{abstract}

The goal of this project is to design a small scale Vertical Axis Wind Turbine, which is capable of producing electrical power even with low wind velocity. It can be placed on road dividers, sidetracks of train or remote places i.e. villages, military camps, where it is not economical to transmit power from power plants. Implementation of such project would reduce the dependence of an industry or remote houses, on electricity board. 


\section{Acknowledgements}

I am using this opportunity to express my gratitude to everyone who supported me throughout the course of this M.Eng project. I am sincerely grateful to them for sharing their truthful and illuminating views on a number of issues related to the project. It gives me great pleasure in acknowledging my Professor Dr. Kaamran Raahemifar for the constant support and guidance for the success of this project.

I would like to thank my parents and family for being a great example and encouraging me throughout my studies, making this project possible. I am also grateful to Ms. Sunita and Ms. Saakshi for their help and support. 


\section{Table of Contents}

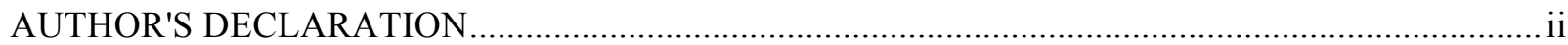

SMALL SCALE VERTICAL AXIS WIND TURBINE ….................................................................iii

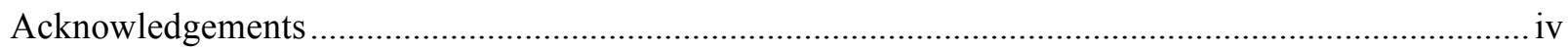

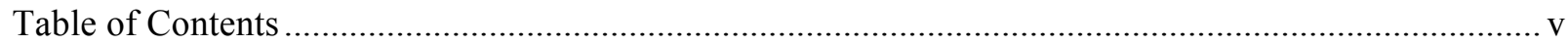

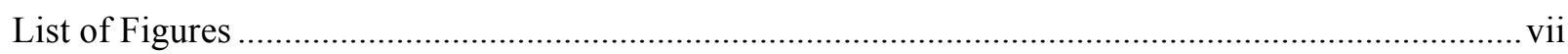

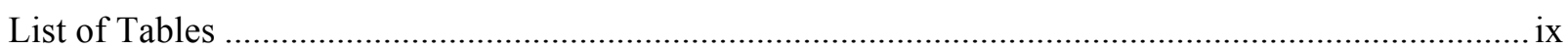

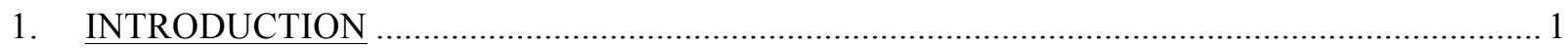

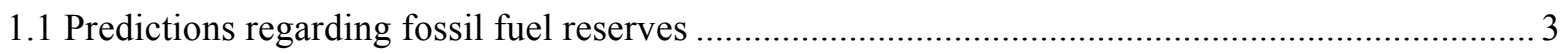

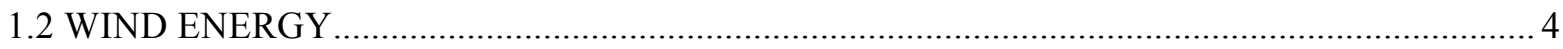

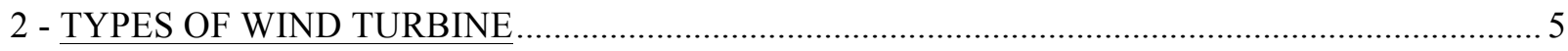

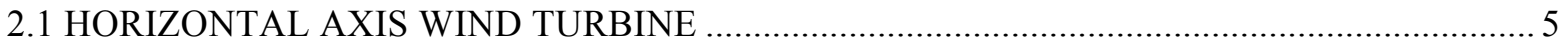

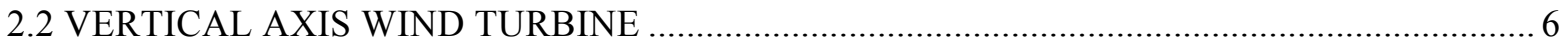

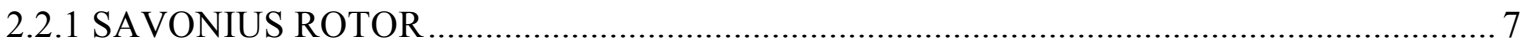

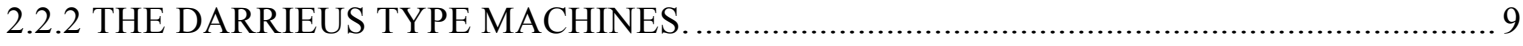

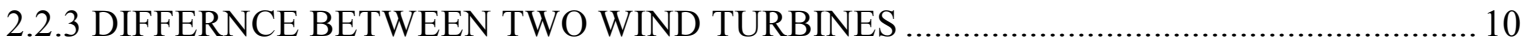

2.2.4 WHY TO GO FOR VERTICAL AXIS WIND TURBINE? ............................................. 11

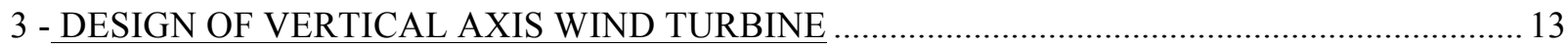

3.1 TYPES OF VERTICAL AXIS WIND TURBINE …............................................................. 13

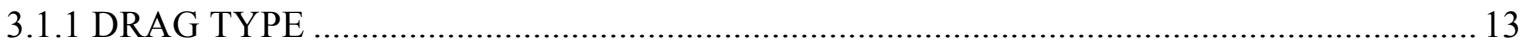

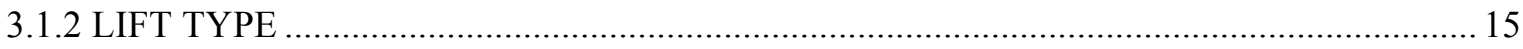

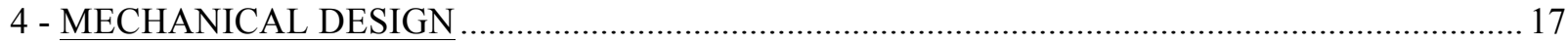

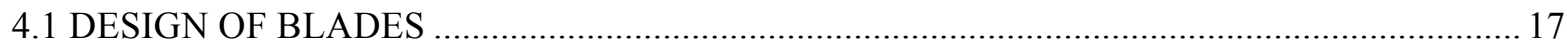

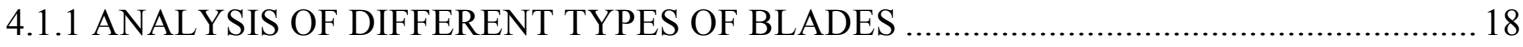

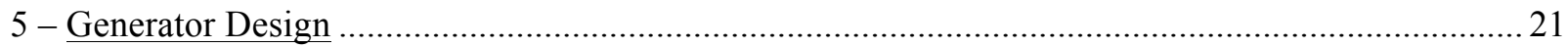

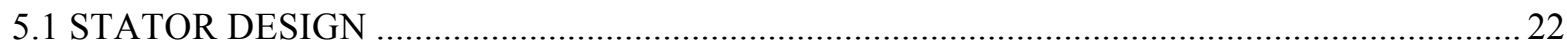

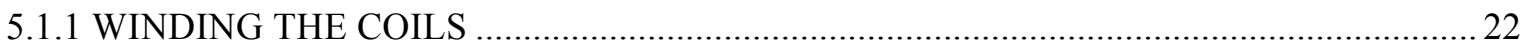

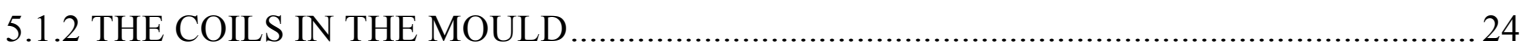

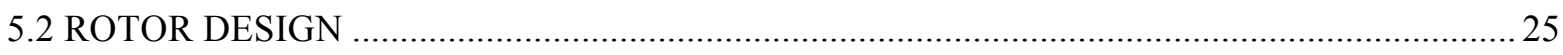

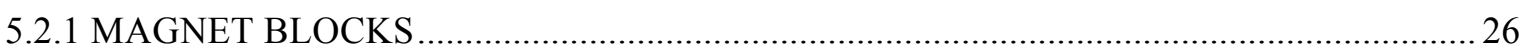

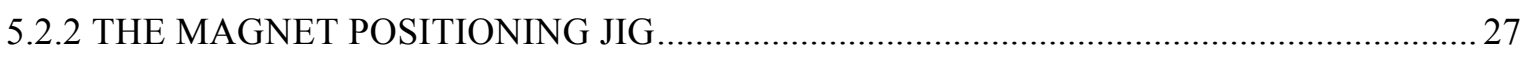

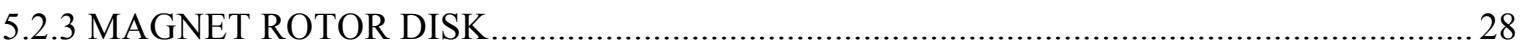


5.2.4 ALTERNATIVE SHAPE: AN OCTAGON 28

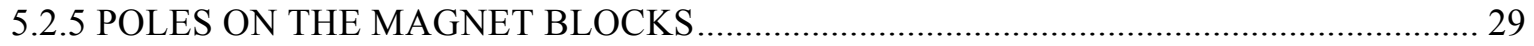

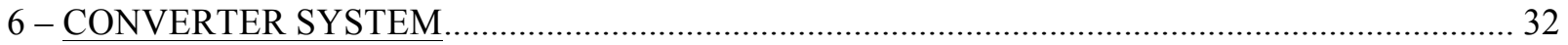

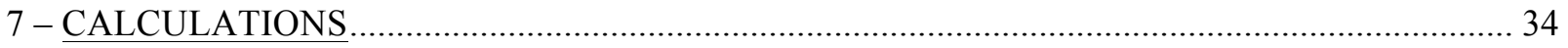

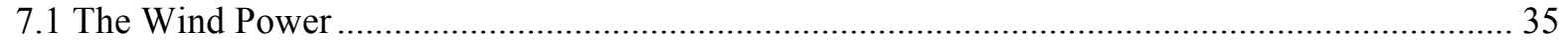

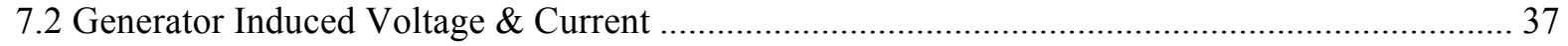

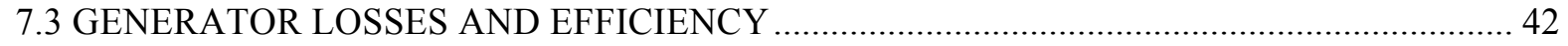

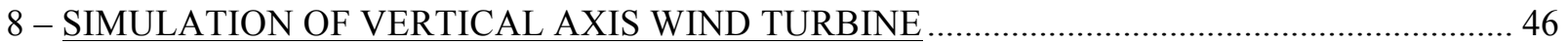

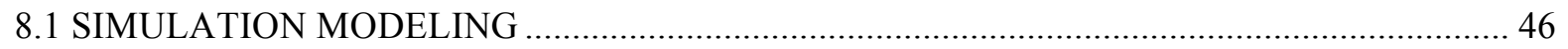

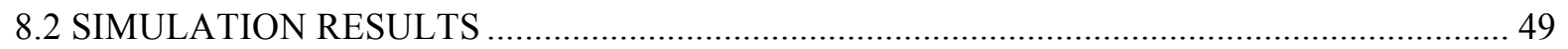

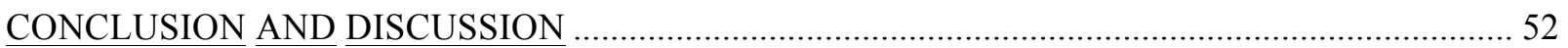

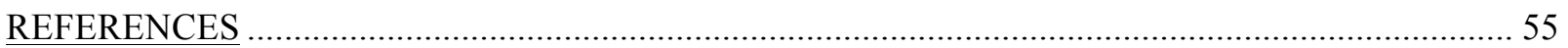

Appendix A MATLAB CODE FOR VAAWT CALCULATIONS....................................................... 58

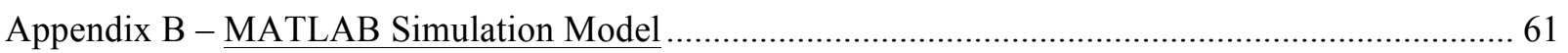




\section{List of Figures}

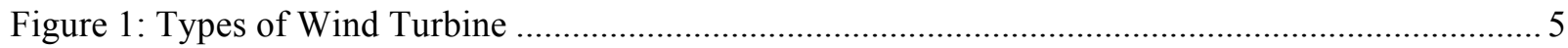

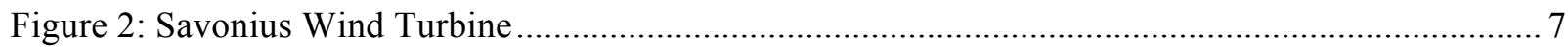

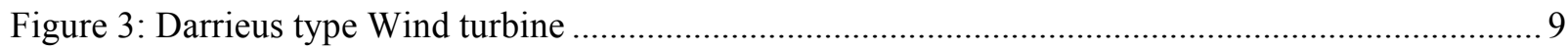

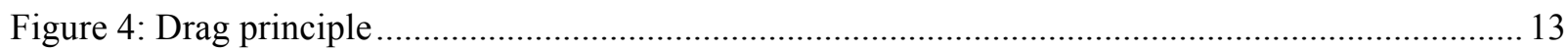

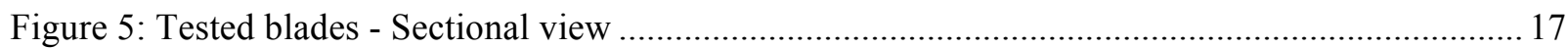

Figure 6: Tested blades: Variation of RPM with air velocity for the .................................................... 18

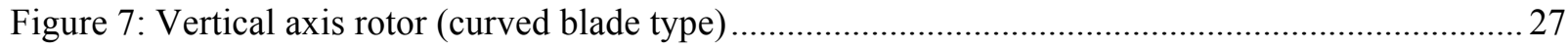

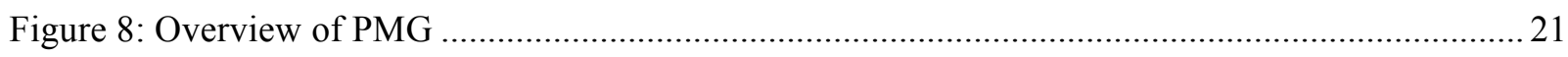

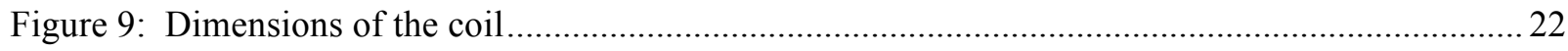

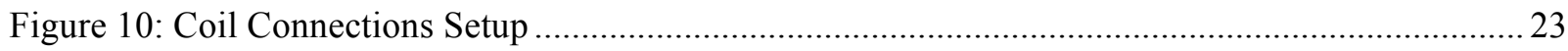

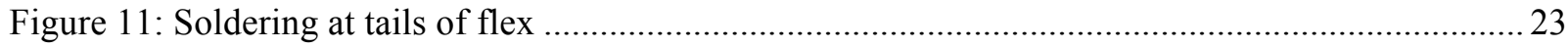

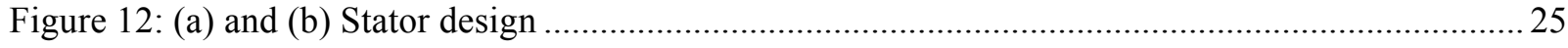

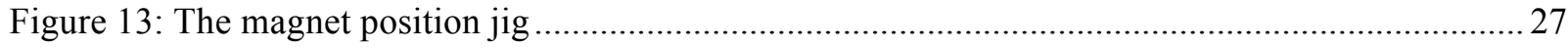

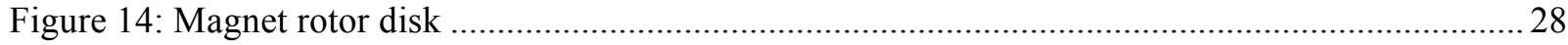

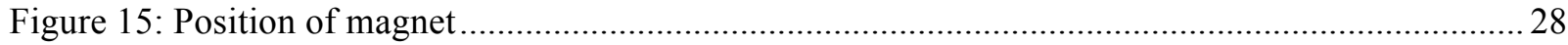

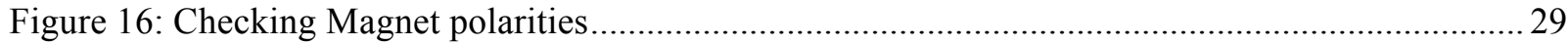

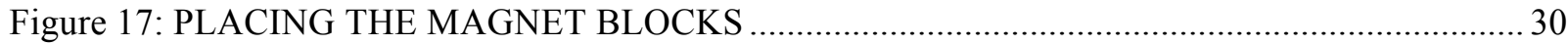

Figure 18: Complete Upper and Lower Magnet rotors ..................................................................... 30

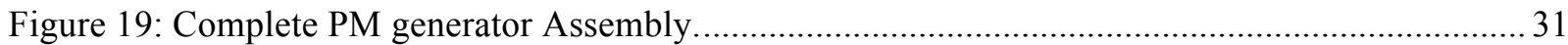

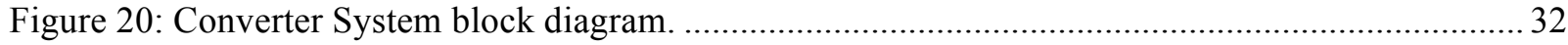

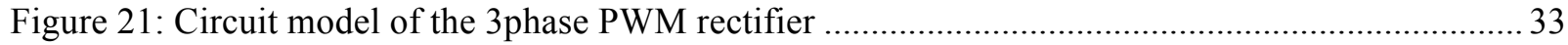

Figure 22: Rayleigh distribution - Probability of Wind Power ......................................................... 34

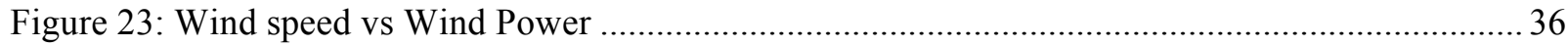

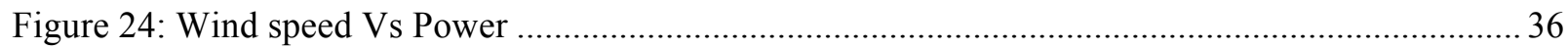

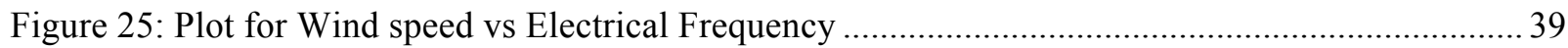

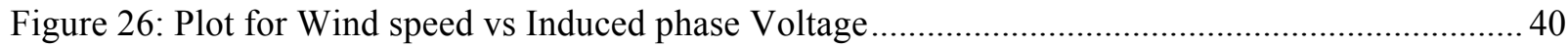

Figure 27: Plot for Wind speed vs Induced Line Voltage ................................................................... 41

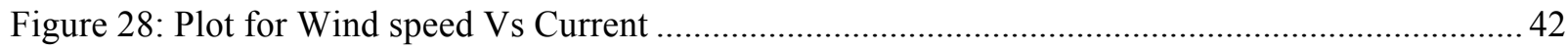

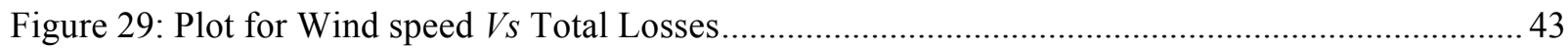

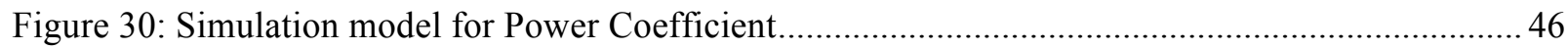

Figure 31: Simulation model for Mechanical power sub-system .......................................................... 47 


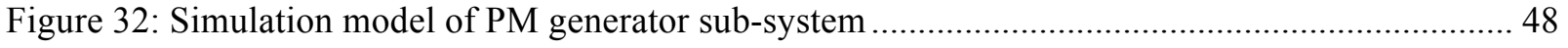

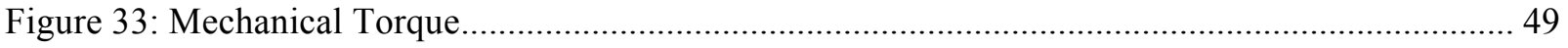

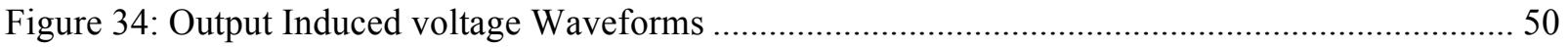

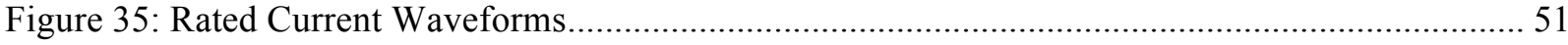




\section{List of Tables}

Table 1 Comparison between two wind turbines......................................................................... 10

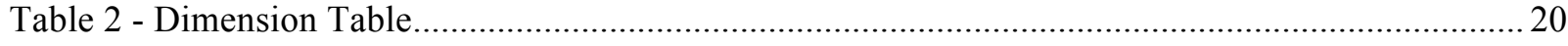

Table 3 -Calculation for electrical power output, No of Hours/year, Annual Energy generated at various

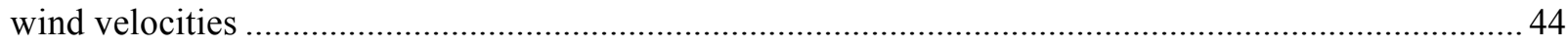

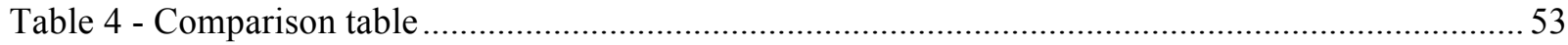





\section{INTRODUCTION}

The population is rapidly growing, and individuals are becoming more and more dependent on technology. As the need, and sometimes more likely, the desire to lead a technical life increases daily, the demand for power in the form of electricity has peaked to an ultimate high. There is a direct relationship between energy consumption and the development of our society. With the population increasing rapidly and improvements in living standards, the future of energy shortage is quickly approaching. Major sources of electrical power generation are non-renewable energy sources and as we know resources for such energy sources are limited and they are sources of pollution in our environment. Now or later, we will have to maximize the use of renewable energy sources. Currently, the most common conventional practices for renewable energy use horizontal wind turbines.

Basic models of wind generation describe air in motion generated from a pressure gradient will generate wind. Solar light rays will heat up the air and such heated air will flow upwards. Other surrounding air will attempt to replace it. This is called global convective circulation; it will create wind or air flow. Science describes solar and wind energy as separate entities, but essentially they are linked together to produce one another. Wind is created by solar energy, in other words, sunrays illuminating earth. During daylight, air heats up rapidly compared to water, and this in turn creates wind flow from water to land. The opposite occurs overnight, as this process reversed and the land cools faster. Another mechanism of wind is caused by hillsides. The air around the slope surface during the day is heated up during the daytime, and cools in the evening. Wind speed increases with height, latitude, altitude and topography of the location in turn affecting the nature of the wind.

Although electricity is a key component of our day-to-day lives, critics will always have something to say. Energy production is criticized as a pollutant to our already deteriorating planet. Although true, electricity has always been, and will increasingly continue to be an essential key to society's livelihood, and for this it is essential to find alternative 
sources. Wind power is the most effective form of electricity production without emitting pollution.

Wind Power is the up and coming form of electricity generation for the future. Essentially, the kinetic energy of wind is converted into mechanical energy for the production of electricity. The most common and familiar machine for generating wind power is a horizontal axis, consisting of a number of blades rotating about a central axis, known as horizontal axis wind turbines or HAWT.

Wind blowing against the blades of the wind turbine, allows the blades to rotate about the axis, which produces a very valuable source of renewable energy by the repetitive rotational motion. Wind turbines produce rotational motion, and the key component, which rotates to create the wind energy, is called the rotor. The conversion of wind energy into electrical energy is conducted by the connection of the turbine to an electric generator.

An alternate form of producing wind energy, which is a modified version of the Horizontal Axis Wind Turbine (HAWT), is the Vertical Axis Wind Turbine (VAWT) model. An advantage of the VAWT model over its counterpart is that it operates independent of the direction of the wind. A key component of the Horizontal Axis Wind Turbine is that it requires a YAW system. YAW systems are required in order to guide the turbine towards the direction of the wind, however this is not required for the vertical axis wind turbines. VAWT blades will rotate regardless of wind direction, this allows for cost efficiency during the manufacturing process.

All Vertical Axis Wind Turbines are functioning by lift or drag principles. This research has been conducted to demonstrate the efficiency and productivity of a Vertical Axis Wind Turbine, with a Savonius Rotor. A Savonius Rotor principally provides lift force but it is 
practically a drag device. Due to the higher solidity of Savonius Rotor, it provides higher starting torque compared to others.

The power produced by the generator can be stored in a battery and can be used to power offices, streetlights, and household appliances. This wind turbine is portable, therefore can be used on any expressways or busy highways. This turbine can be used commercially for low power applications. The implementation of such a project would reduce the dependence of a company or industry on the electricity board. Overall, this form of power generation, specifically Vertical Axis Wind Turbines, are fit serve each individual, family, community and society as a whole.

\subsection{Predictions regarding fossil fuel reserves}

The majority of the earth's consumable energy is supplied by fossil fuels. It is a reasonably concentrated and pure source of energy that is technically easy to exploit, which in turn provides a cheaper energy source. The world's current energy consumption is made up of coal $33 \%$, oil $27.7 \%$, natural gas $21.3 \%$, nuclear $11.2 \%$, hydroelectric $6 \%$, and others make up the remaining $0.8 \%$.

Fossil fuel reserves are depleting, and it is imperative to note:

- The fuel cells for nuclear power plants are at an all-time low, and experts predict, at the current rate of use, this reserve will only be enough to supply for the next 45 years.

- Experts also predict, oil production will dramatically reduce after a plateau in 2020.

- Coal reserves are also diminishing by the day, as predictions state approx. 200 years' worth of reserves remain 
Such facts are encouraging scientists to look for an alternate method of power production, which leads to the renewable energy source avenue in order to meet and exceed the continuous growth for energy.

\subsection{WIND ENERGY}

The sun is the most important source for wind energy production. When sunrays shine upon the surface of the earth, it causes the surface to heat up; as a result creating the formation of uneven winds. The wind's kinetic energy can assist to rotate and run the wind turbines, but essentially the generated power output is dependent on the wind speed. A general rule of thumb for ideal wind requirements is wind ranging between approximately six to eight meter/sec. In reality, there are very few open land regions where winds with this prevailing speed can be found. If this were possible, wind power would be the leading source of energy.

Wind power is one of the most cost effective renewable sources of energy, and it has become one of the most rapidly growing energy production sources of our generation. The long term predictions for wind power generation is thought to have the technical potential to be five times the current worldwide consumption of energy, which translates to forty times the current electricity demand. 


\section{2- TYPES OF WIND TURBINE}

There are two types of wind turbines: Horizontal Axis Wind Turbine (HAWT) and Vertical Axis Wind Turbines (VAWT).

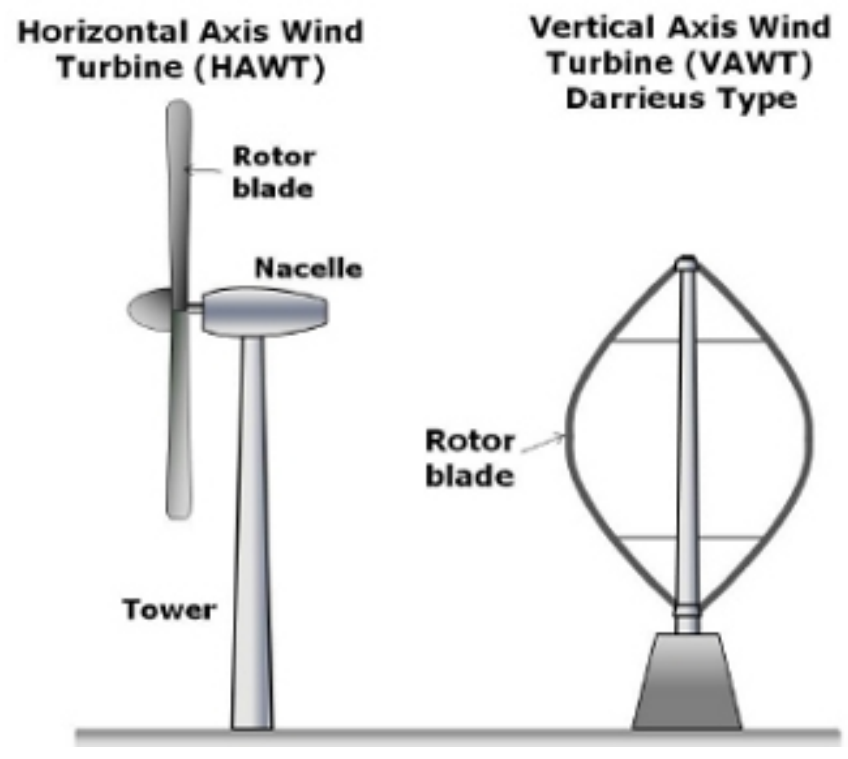

Figure 1: Types of Wind Turbine

1) Horizontal Axis Wind Turbines (HAWT): The figure above (left) is the most popular model of wind turbines, in which the rotational axis of the rotor is parallel with the ground.

2) Vertical Axis Wind Turbines (VAWT): the figure above (right) is the proposed model of wind turbines for this project. Its rotational axis is perpendicular to the ground.

\subsection{HORIZONTAL AXIS WIND TURBINE}

A horizontal axis wind turbine's rotor rotates parallel with the ground. HAWT's consist of three blades usually, however sometimes it may vary. The main responsibility of the rotor is to take the motion of the wind, which is linear, and convert it into rotational energy that will be used to drive energy directly to the generator. 
The process of creating usable energy is as follows: wind is passed through the blade surfaces (shaped like airfoils) and high pressure wind strikes first around the upper side, which in turn creates low pressure region above the airfoils. The difference between high and low wind pressure surfaces creates aerodynamic lift. The blades of the wind turbines should be built in such a way that they have high lift to drag ratio. The Optimum value of this ratio will result in high efficiency of turbine.

Most of the modern HAWT consist of three blades. Traditional HAWT had multi blade turbines. These rotors have a ratio, which is proportionate in strength and weight. This has an advantage of simplicity and cost efficiency. There are two famous horizontal axis multi blade type turbines: Dutch type and Sail type wind turbines. The original horizontal axis model was the Dutch type HAWT. At that time, the blades were carved from wood. Another model more recent is the Sail type HAWT. The blades in this model were developed from nylon, plastic or cloth, and the number of sails used varies.

\subsection{VERTICAL AXIS WIND TURBINE}

VAWT's axis of rotation is perpendicular to the ground. Vertical Axis Wind Turbines are not as popular as traditional HAWT but there is a lot of scope for research in this field. Darrieus rotor has curved blades that minimize bending stresses in normal operations and force on the blade caused by rotation is purely tension. Giromill rotor has straight blades that generate lift forces to convert wind energy into rotational mechanical energy. Savonius rotor has "s" shaped blades, which make the rotor more efficient.

Many researches are done on VAWT design. Few rotors were designed on drag principle and few were designed on lift principle. Both have advantages over each other in different aspects. Savonius Rotor principally provides lift force but it is practically a drag 
device. This rotor has high starting torque advantage, however the downside of this rotor is that it has lower efficiency compared to lift turbines.

\section{Advantages of VAWT over traditional HAWT:}

- The VAWT does not get subjected to continuous cyclic gravity loads because the blades do not rotate tip to tail.

- Generator and other control systems can be installed on the ground, thus reducing manufacturing and maintenance costs.

- Yaw system is not required as VAWTs accommodate to any wind direction.

The largest disadvantage facing the development of vertical axis wind turbine is the lack of knowledge and research on the phenomenon. This handicap is rapidly being removed.

\subsubsection{SAVONIUS ROTOR}

Savonius rotor is developed by S.J. Savonius in the 1920s. This rotor is simple in construction and operates at low wind speed. Hence, this wind turbine is popular in recent days. Wind from any direction forces this rotor to rotate. Mechanical power generated from this rotor can be implemented in variety of methods, which includes water pumping, generate electricity, grain winnowing and many more.
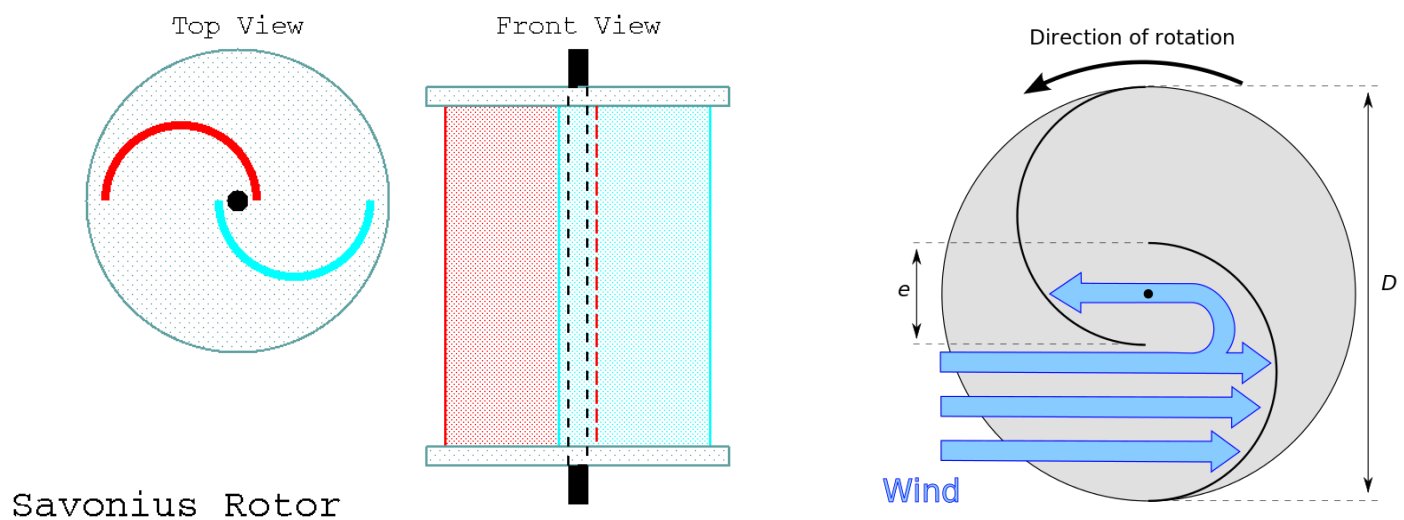

Figure 2: Savonius Wind Turbine 
Above figures shows Savonius wind turbine's top and front view. Two "C" shaped blades are installed on the vertical axis, in a way that they illustrate an "S" shape.

Overlapping of both blades at the center is intended in order to extract power from reduced pressure wind. When wind strikes on these blades, the cupped part of the blade experiences more wind power compared to rounded part. The gap between two blades helps to rotate them, when the wind is blowing from any direction.

\section{ADVANTAGES OF SAVONIUS ROTOR}

- It has vertical axis rotation, which eliminates costly gear system to transfer energy produced by blades.

- This rotor is more useful and less dependent on storage of supplementary power.

- Ground level mounting and gearing permits easy access and maintenance.

- Tower is not required, so manufacturing cost is low.

- This turbine is self-starting and has high starting torque.

\section{DISADVANTAGES}

- When it needs to be installed on the tower, this rotor is not useful.

- Efficiency of this rotor is low, compared to lift type turbines.

- It operates on low speed only. 


\subsubsection{THE DARRIEUS TYPE MACHINES.}

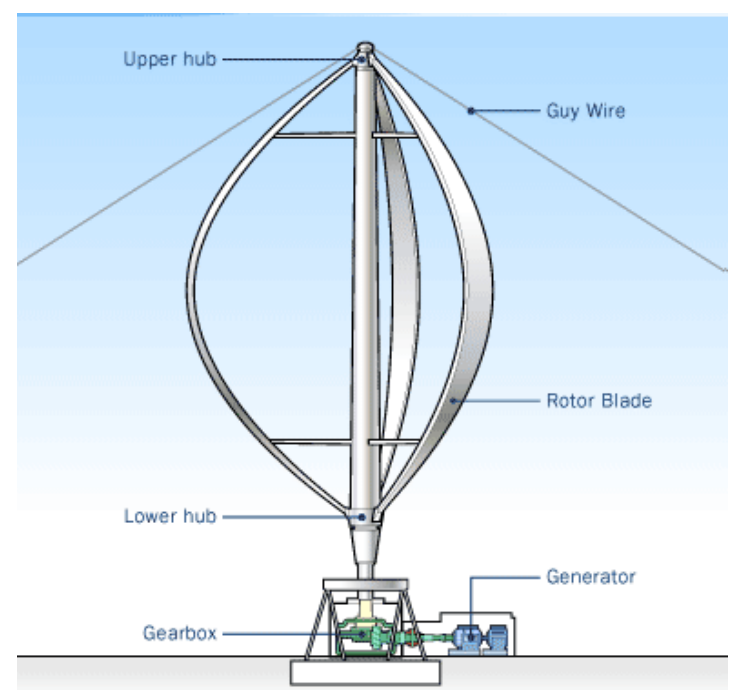

Figure 3: Darrieus type Wind turbine

A French engineer known as G.J.M. Darrieus invented the Darrieus wind turbine in 1925. Along with many benefits of this machine, an important benefit is that the machine is designed in a way that protects the blades from bending pressure in regular function. This machine is built using two to three thin, arched blades. The Vertical shaft is attached to both ends of the blade, so the force in blade created by rotations is pure tension. This will generate mechanical torque on center shaft. The shaft will transfer mechanical energy to the generator in order to generate electricity.

\section{ADVANTAGES}

- The power coefficient and TSR are significantly better than those of the S rotor.

- The key benefit of this design is that the rotor blades allow wind that comes from any direction.

- Yaw control system is not needed for this rotor.

- This turbine can be installed at ground level.

- This rotor has high efficiency and high-speed operation. 
- Potentially low capital or manufacturing cost.

\section{Disadvantages}

- This rotor is not self-starting, therefore would need external starting boost.

- The power output efficiency of the rotor is lower than a conventional horizontal rotor

- As the rotor is operated closer to the ground, the problem is that it may lead to lower velocity wind, compared to HAWT.

- High torque braking system is required, that increases manufacturing cost.

\subsubsection{DIFFERNCE BETWEEN TWO WIND TURBINES}

Table 1 Comparison between two wind turbines

\begin{tabular}{|l|l|}
\hline \multicolumn{1}{|c|}{$\begin{array}{l}\text { HORIZONTAL AXIS } \\
\text { WIND TURBINE }\end{array}$} & \multicolumn{1}{|c|}{\begin{tabular}{c}
\multicolumn{1}{|c|}{$\begin{array}{l}\text { VERTIACAL AXIS } \\
\text { WIND TURBINE }\end{array}$} \\
\hline $\begin{array}{l}\text { 1. In the case of horizontal axis wind } \\
\text { turbine's air strikes from one direction } \\
\text { only. }\end{array}$
\end{tabular} $\begin{array}{l}\text { 1. In case of vertical axis turbine air } \\
\text { strikes from both directions. }\end{array}$} \\
\hline $\begin{array}{l}\text { 2. In horizontal axis wind turbine } \\
\text { generator, gearbox cannot be placed on } \\
\text { the ground. }\end{array}$ & $\begin{array}{l}\text { 2. In the case of VAWT the gearbox, } \\
\text { generator and control system will install } \\
\text { on the ground. }\end{array}$ \\
\hline $\begin{array}{l}\text { 3. In horizontal axis wind turbine, tower is } \\
\text { essential; hence cost of erecting is high. }\end{array}$ & $\begin{array}{l}\text { 3. In the case of VAWT tower does not } \\
\text { essential for the machine, hence reducing } \\
\text { the manufacturing cost. }\end{array}$ \\
\hline $\begin{array}{l}\text { 4. In horizontal axis wind turbine we need } \\
\text { a yaw system. }\end{array}$ & $\begin{array}{l}\text { 4. In vertical axis wind turbine we don't } \\
\text { need yaw system. }\end{array}$ \\
\hline $\begin{array}{l}\text { 5. On horizontal axis wind turbine control } \\
\text { system is required. }\end{array}$ & $\begin{array}{l}\text { 5. There is no requirement of control } \\
\text { system which also reduces the overall cost } \\
\text { and frequent maintenance. }\end{array}$ \\
\hline
\end{tabular}




\subsubsection{WHY TO GO FOR VERTICAL AXIS WIND TURBINE?}

As stated previously, this project is more suitable to places like road dividers. The aim is to utilize the wind draft produced by moving vehicles to generate electricity. This can be achieved by placing small vertical axis wind turbines on the road divider.

When vehicle is passing with certain speed, vacuum is created after the vehicle has gone-by. This creates air turmoil. The vacuum is filled with the surrounding air rushing in the direction of vehicle. The air involved has a large quantity and sufficient speed, and this air can be used to rotate the blades of a small turbine. This enables us to generate some electricity to charge a $12 \mathrm{~V}$ battery.

If the flow of traffic is continuous, the turbine can be made to rotate continuously to generate large energy. By designing suitable blades of the turbine for typical traffic conditions we can obtain optimum results. A horizontal axis wind turbine cannot be implemented here because it can work with unidirectional wind only. While the wind turbine to be used in this project will intend to work with bidirectional wind, as it has to be put on places like road dividers. Moreover, even horizontal axis wind turbines also can be used with bidirectional wind by adding a feature of yaw system, which makes it more costly. While such kind of yaw system is not necessary in VAWTs. In the case of VAWT's, the generator as well as the gearbox will be commissioned at ground level. That way we can avoid tower construction and can reduce overall cost.

The main constraint of this turbine is that when it is placed at road dividers, the speed of the turbine largely depends upon the traffic density and the kind of vehicles, whether large or small. It takes almost the entire day for charging. This again depends on the traffic density as well as on natural wind velocity. The overall efficiency is less i.e. $20 \%-30 \%$. For this purpose we are using high efficiency generator. We are using aluminum blades since it's cheap as well as light and possesses sufficient cost is substantially less. The most unique feature of 
this design is that there is no requirement of control system, which also reduces the overall cost and frequent maintenance. Often in turbines, generators are connected horizontally using sprockets, pulleys, belts, gearings, etc. But here we have connected generator directly to the hub to overcome mechanical losses. Blades are connected using cross arms, which make them robust. 


\section{3-DESIGN OF VERTICAL AXIS WIND TURBINE}

\subsection{TYPES OF VERTICAL AXIS WIND TURBINE}

Blades of the wind turbines are classified in two categories;

- Drag type

- Lift type

\subsubsection{DRAG TYPE}

In reference to the tower, if the rotor is downwind, the wind turbine is called drag type or downwind type. The drag adjusts its motion, according to the frontal area of an object if it were facing the wind. Designing an object that travels at a fast pace through fluids is an efficient idea. This theory helps to explain the reason why the construction of cars, submarines and bicycle helmets are built in a long shape.

Drag type machines consist of an advantage in which they may have been constructed without the use of a yaw mechanism. This occurs when both the nacelle and the rotor consist of an appropriate design that makes it follow the wind. In addition, a very important benefit of this rotor is that it is made to be flexible. This advantage applies to how much the machine weighs, as well as the structural dynamics. In order to lighten the load of the tower, the blades are designed to bend at higher wind speeds. In other words, the most important benefit of this downwind machine is that it is built using less weight in comparison to lift type machines.

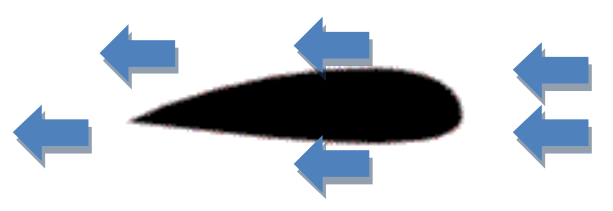

Figure 4: Drag principle 
Above figure shows the drag type rotor principle. When blade is moving to the right, blue arrows indicate the direction of drag force.

The shape of the object has an impact on the drag. The coefficient $C_{D}$ is a measure used for determining the size of the drag for a specific shape. $C_{D}$ is defined as the drag force in proportional to the frontal area of an object. A typical automobile that would be seen in present day has a $C_{D}$ within a range of $0.2-0.35$. In addition, a jogger has a $C_{D}$ of approximately 0.5 . Meanwhile, a bicyclist who participates in races would have a $C_{D}$ of about 0.45 . However, an airfoil shape that is found on the wings of an aircraft has the smallest $C_{D}$ of 0.03 .

Rotors that are found on wind turbines of today consist of extremely high tip speeds, ranging around $60 \mathrm{~m} / \mathrm{s}$. It is important to use the rotor blades that are in an airfoil shape in order to acquire a higher level of effectiveness.

\section{Tip Speed Ratio}

$$
T S R=\frac{\text { Tip Speed of the blade }}{\text { Wind speed }(\mathrm{m} / \mathrm{s})}
$$

Tip speed ratio is the relation between tip speed of the rotor and wind speed. With the wind speed being a varying factor, the accelerating speed of the rotation of the wind turbine depends upon the ratio of the tip speed. In order to generate electricity there is a need for increased speed of rotation. When comparing the maximum tip-speed, the drag type ratios result in about one, while lift style wind turbines results in about ten. To compare between the two, the lift-type wind turbine is the best option for this, as it requires an elevated rotational speed.

How well the wind turbine is able to perform is solely dependent on the rotor and how many blades are used to construct it, as well as the overall area that is being covered. It is significant for the wind to be able to flow smoothly over the blades in order for the wind 
turbine to be able to perform as it is expected to. Detailed specifics about the space between the blades are important to keep in mind, as it is important to ensure that no problems such as turbulence occur throughout the process. In order to avoid any problems during functioning, it is important to ensure that the wind turbines consist of only two or three blades.

\subsubsection{LIFT TYPE}

Lift type also known as upwind type, is when the rotor of the wind turbine is facing the wind. Being able to avoid the wind shade from behind the tower is the greatest benefit that has been acknowledged for the lift type design. Majority of wind turbine designers prefer to use this exact design. The wind begins to bend in a direction away from the tower, without even reaching the tower. This behavior occurs even though the tower is round and smooth. Thus, there is a slim drop in the amount of wind power every single time the rotor is passing the tower. However, like any other design, the lift type has a downside. This weakness of the lift type design is that the rotor is required to be manufactured to be inflexible and must be distanced from the tower. A yaw mechanism is required within a lift type machine is order to ensure that the rotor is facing the wind.

Looking at the common principles that are found in airplanes, kites and birds, manufacturers of the lift blade design aim for the same properties. The blade is primarily an airfoil or is considered a wing. Various wind speeds and differences in pressure are created between the top and bottom blade surfaces, when the air flows right past the blade. When the pressure is interacted with the lower surface blade, the pressure is much greater, therefore, behaves as to lift the blade. Lift is turned into rotational motion when the blades are joined to the central axis, acting as the wind turbine rotor. When dealing with electricity generation, wind turbines are a better option as they are powered by lift, resulting in acquiring greater rotational speeds in comparison to drag types. 
In order to determine if a VAWT design is dependent on drag or lift, the best way is to refer to the TSR. When the TSR results in a total of above 1, it means there is some amount of lift. Meanwhile, a TSR below 1 means there is mostly drag. The advantage of this is that the design solely based on lift is able to output more power with an increase in efficiency.

\section{SPACING RULE}

In reference to the winds direction, the wind turbine must be aligned perpendicularly. Where wind is unidirectional all day, the spacing between turbines of a row is $2 \mathrm{D}-3 \mathrm{D}, \mathrm{D}$ being the diameter of the rotor. Inter-row spacing is about $10 \mathrm{D}$; normally wind is not unidirectional in that case, a uniform spacing of 5-7D is recommended. Computer software "Micro positioning" is available for this purpose. Internal transformers and cabling will connect the aero generator to the grid. Each turbine will have its own control circuit. Grid connection requires a certain sophisticated protection scheme whose purpose is:

- To isolate the wind farm in case of any internal fault in the electrical system.

- To disconnect the wind farm if there is a fault on any section of utility network (grid). 


\section{4- MECHANICAL DESIGN}

In modern day investigations, there are two different developments of the Savories rotor blades. The investigation consisted of examining the rotational speed in reference to the conventional straight as well as the rotor blades with a curve.

\subsection{DESIGN OF BLADES}

There are four various types of blades which have been utilized in conducting the experiments. The four types of blades are as follows; (a) curved blade, (b) straight blade, (c) aerofoil blade and finally (d) Twisted blade. These four blades are demonstrated in Fig.1. it is evident to be aware that a few investigations conducted on straight and curved blades have currently been carried out.

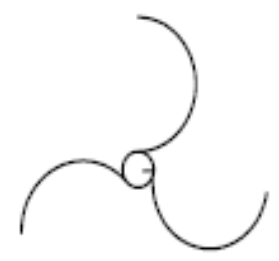

(a) Curved

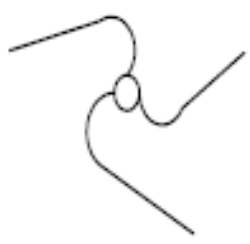

(c) Aerofoil

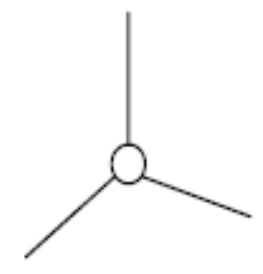

(b) Straight

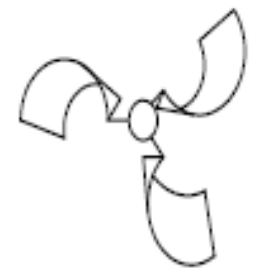

(d) Twisted

Figure 5: Tested blades - Sectional view

In this project design work, there has been redesigning and examination of the straight and curved blades is accomplished. Within the current examination conducted, an aerofoil 
shaped blade has been further designed, invented and tested, as well as a twisted blade. Flattened trapezoidal G.I. sheet was used in manufacturing each blade with equal dimensions of $1.5 \mathrm{~m}$ height and $1 \mathrm{~m}$ width.

\subsubsection{ANALYSIS OF DIFFERENT TYPES OF BLADES}

In reference to air velocities, when testing the ranges, the straight blade has been discovered to have less efficiency in comparison to other blades as shown in the figure below. The reason for this is because there is a balanced quantity of drag force acting on both blades, as they are placed $120^{\circ}$ apart while dealing with the same quantity of air stream.

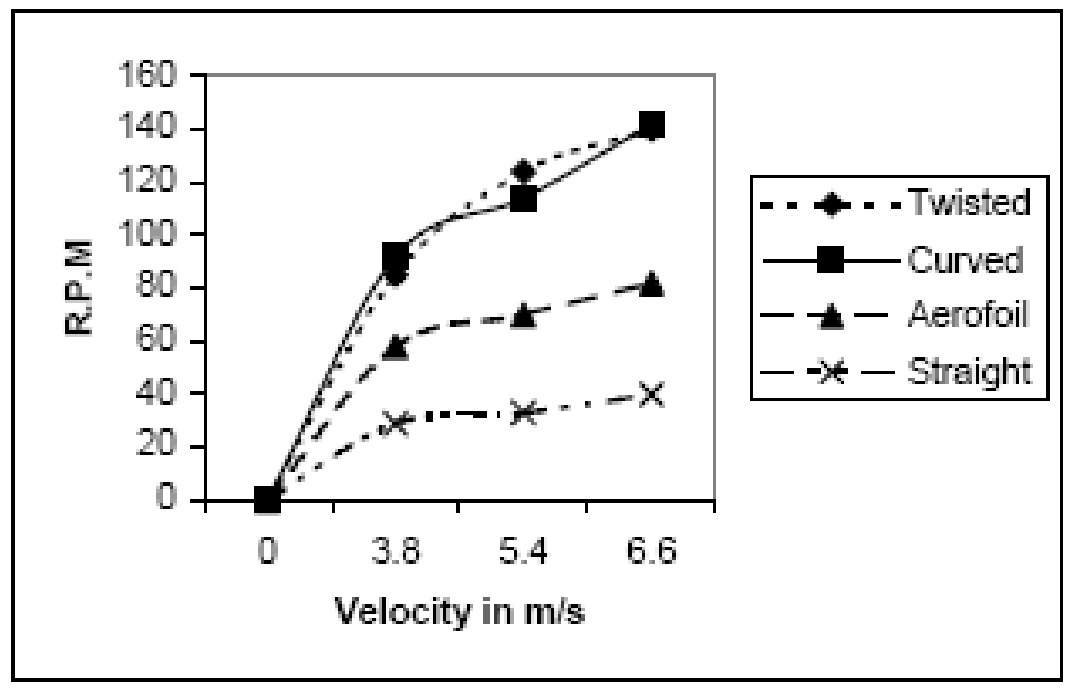

Figure 6: Tested blades: Variation of RPM with air velocity for the

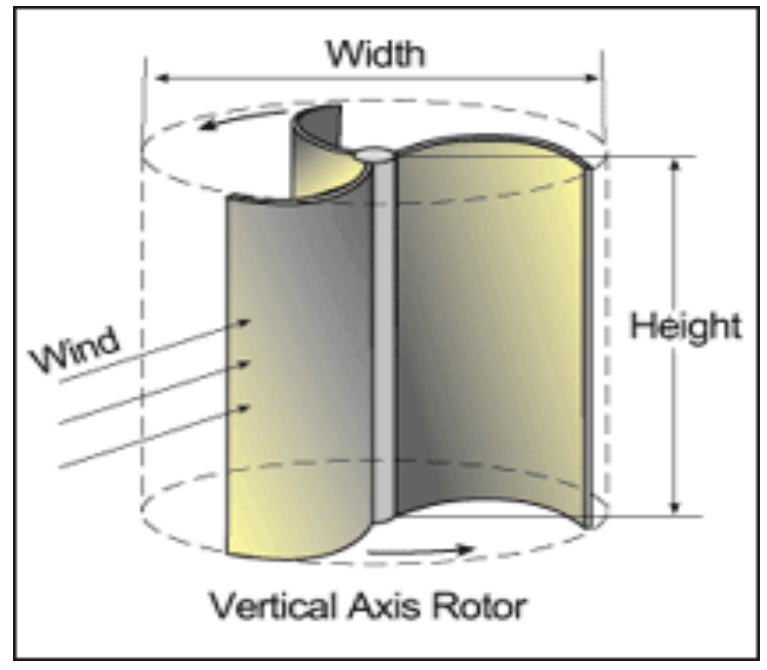

Figure 7: Vertical axis rotor (curved blade type) 
The turbine has three blades at an angle of $120^{\circ}$ to each other. Such design of the blades so that can harness maximum wind energy striking it. The blades are one piece structure folder in the form of an arc, having a curvature less that of a semi-circle. Curved type of design doesn't need much effort to get accelerated compared to other stated designs. Owing to the fact that, GI steel sheet has a long list of advantages like good tensile and compressive strength, rugged and comparative long life, high stiffness to weight ratio, good resistance against corrosion, it is employed for the formation of blades.

Glass fiber reinforced plastic (GRP) would have been the ideal choice for the blades but this would become too expensive and hence nullified the objective of producing a low cost wind turbine. The dimensions of the blades are dependent on the width of the road divider and considering it chosen the dimension of the blades as $100 \times 50 \mathrm{~cm}^{2}$.The cross-arms are Y-shaped steel roads which are square in cross-section.

The wind turbine's center is the connecting section between the blades leading to the main shaft. Each blade is connected to the hub with the help of three steel rods. These rods are welded to the hub as well as bolted to the blades. The length of the cross arm is $80 \mathrm{~cm}$. We have used mild steel for the hub. This is used in order to make the structure stable. The hub is joined to the main shaft. Solid M.S. rod is used to make the main shaft. In addition, the main shaft is made to pass thought two bearings. The two bearings are supposed with the help of a bearing house placed top and bottom of the blade. The generator is rested on wooden base, which is kept on the ground. By keeping it on the ground the center of gravity of the entire system is lowered. 
Table 2 - Dimension Table

\begin{tabular}{|c|c|c|}
\hline SR. NO & PARTICULARS & DIMENSIONS \\
\hline 1. & Width of each blade & $0.9 \mathrm{~m}$ \\
\hline 2. & Height of each blade & $1.3 \mathrm{~m}$ \\
\hline 3. & $\begin{array}{c}\text { Angle between the cross } \\
\text { arms }\end{array}$ & $120^{\circ}$ \\
\hline 4. & Overall height & $1.5 \mathrm{~m}$ \\
\hline
\end{tabular}

Table shows the blade dimensions for small scales vertical Axis wind turbine. Width \& radius is most important design parameter of blade. 


\section{5- Generator Design}

Permanent magnet generator is used for small-scale vertical axis wind turbine. Which can also be referred to as an 'alternator', as its key purpose is to generate alternating current (AC). It will generate three phase AC low voltages, which creates 'direct current' (DC) by the use of converters for charging twelve volt batteries.

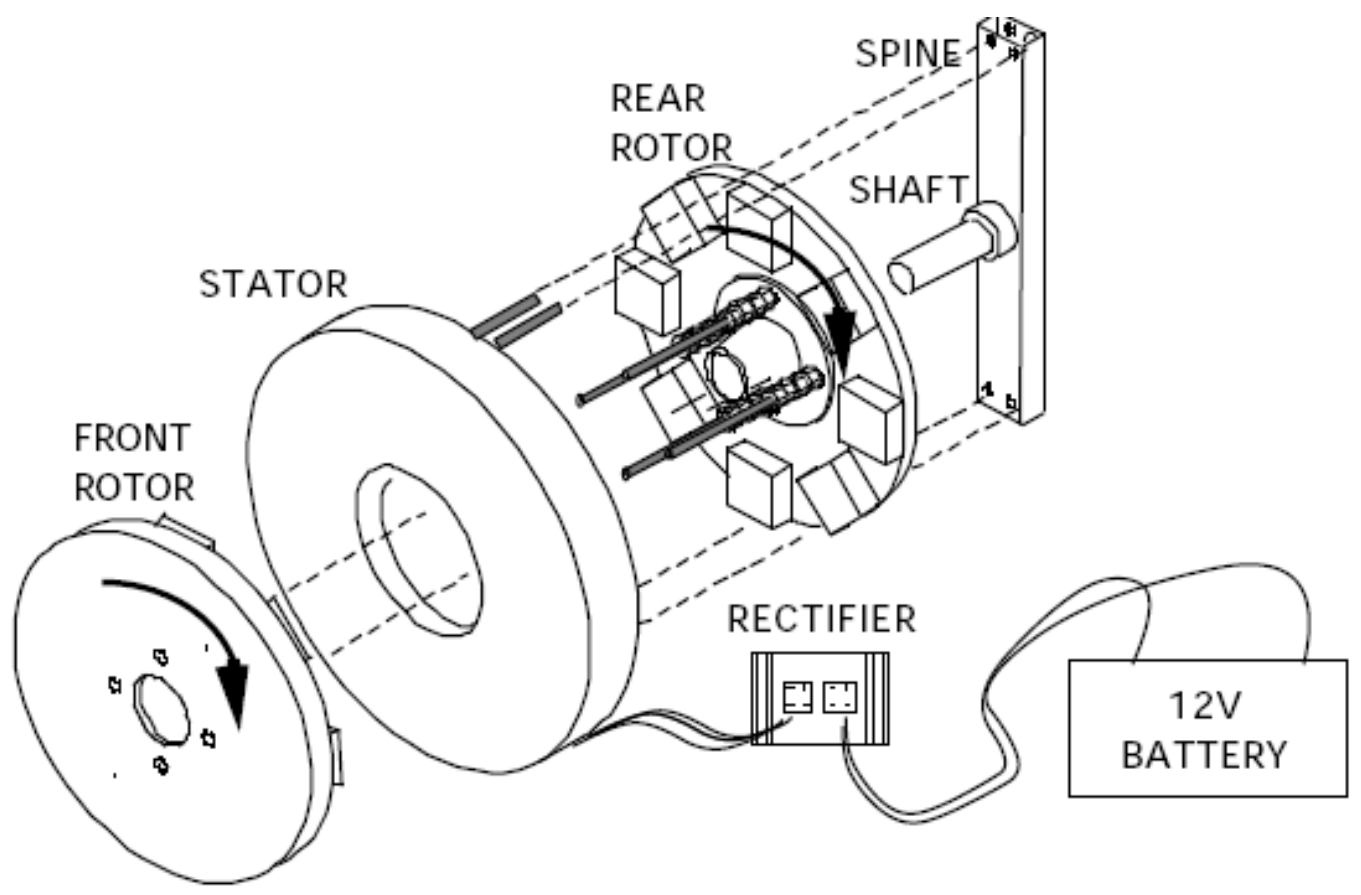

Figure 8: Overview of PMG

The figure above, which is depicting a Permanent Magnet Generator. The main components of Permanent Magnet Generator are a stator disc which contains twelve stator winding coils. Also, two magnet rotor discs which contain 32 magnets (16 magnets each). There is also a shaft that's key role is to connect the magnetic rotor discs to the wind turbine blades. Lastly, the converter system is implemented to convert variable generated power to the 
regulated DC power. The battery unit is required to store generated power for use for industrial and household appliances.

\subsection{STATOR DESIGN}

Whenever the conductor cuts the magnetic lines of force an EMF is induced in that conductor, this is the electromagnetic induction law for generators. Three phase AC power is induced in stator coils as per this law. There are twelve 1200 turns coils are used to make the stator winding. The size of the wire for these coils were decided by calculating current flow in the generator or stator. The three phase output from the stator coils is supplied to the converter system in order to convert the AC power to regulated DC power.

The size of the wire for these coils were decided by calculating current flow in the generator or stator. This design is conducted considering low-medium wind speed application. For higher wind speed operation, we would be required to change the size of the wire of the coils, this change will reduce copper losses in the stator winding. Another method to increase current carrying capacity of the coils is by changing the connection method for the coils.

\subsubsection{WINDING THE COILS}

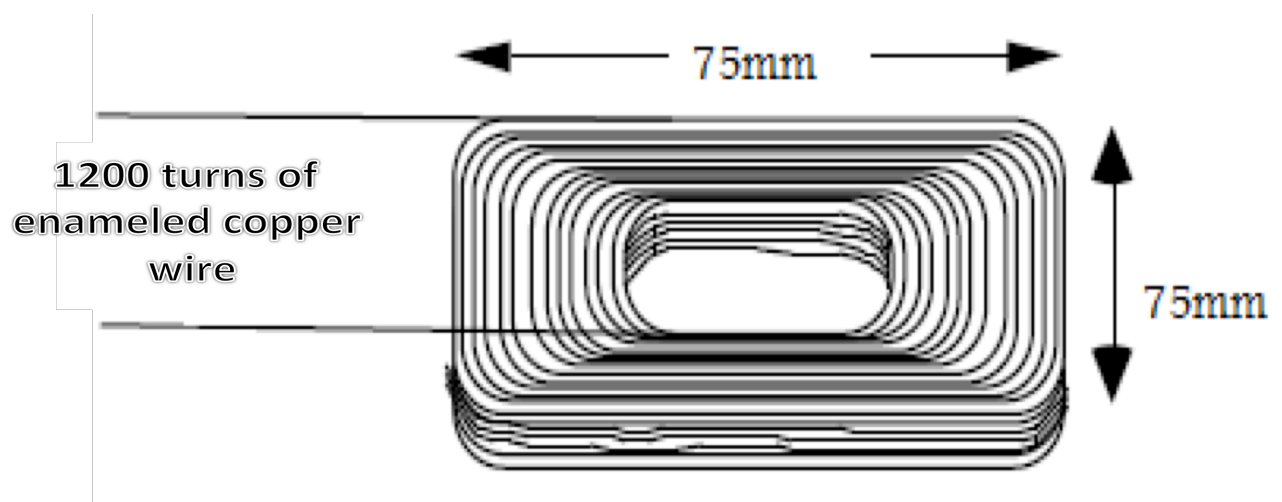

Figure 9: Dimensions of the coil 


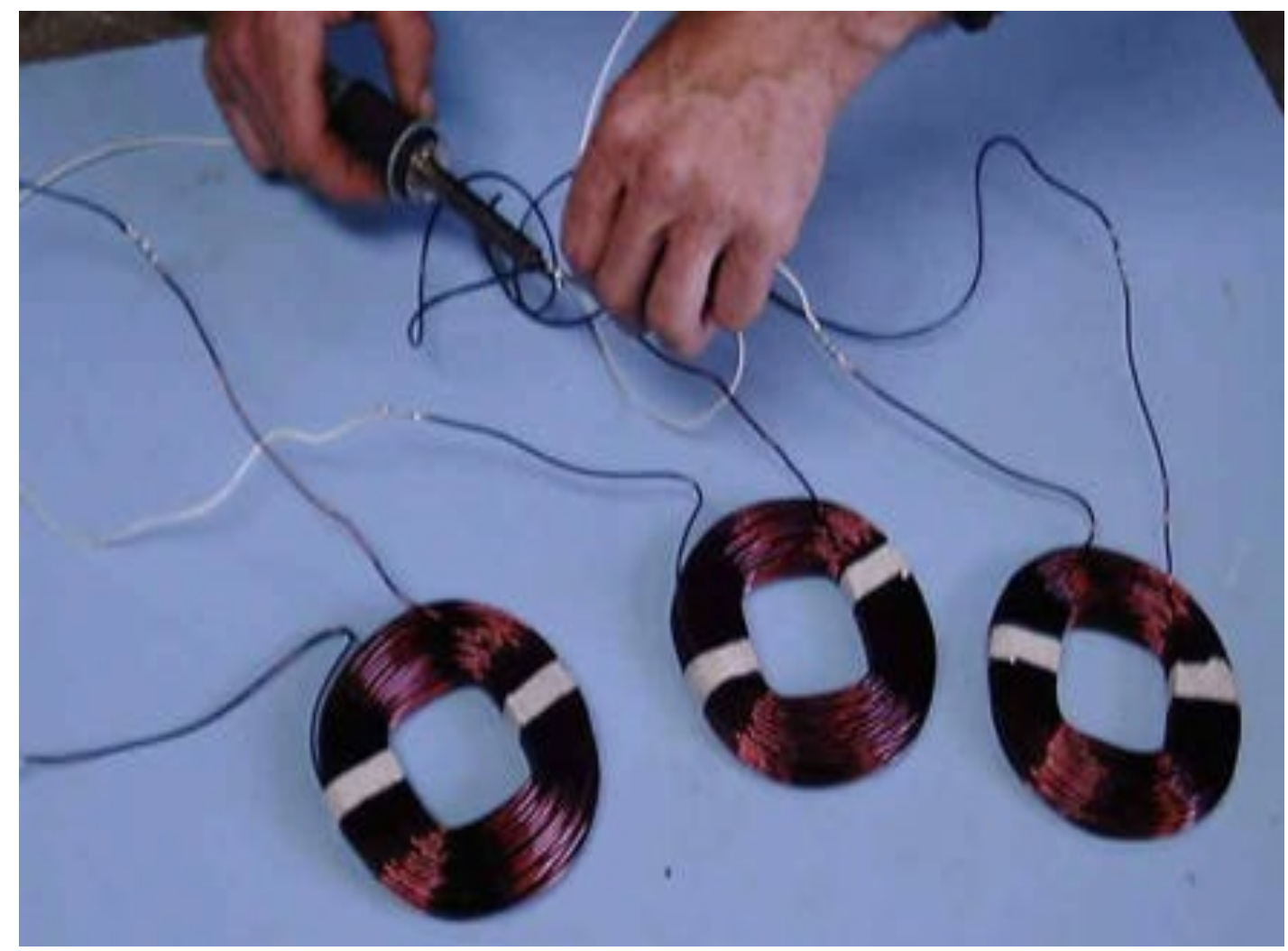

Figure 10: Coil Connections Setup

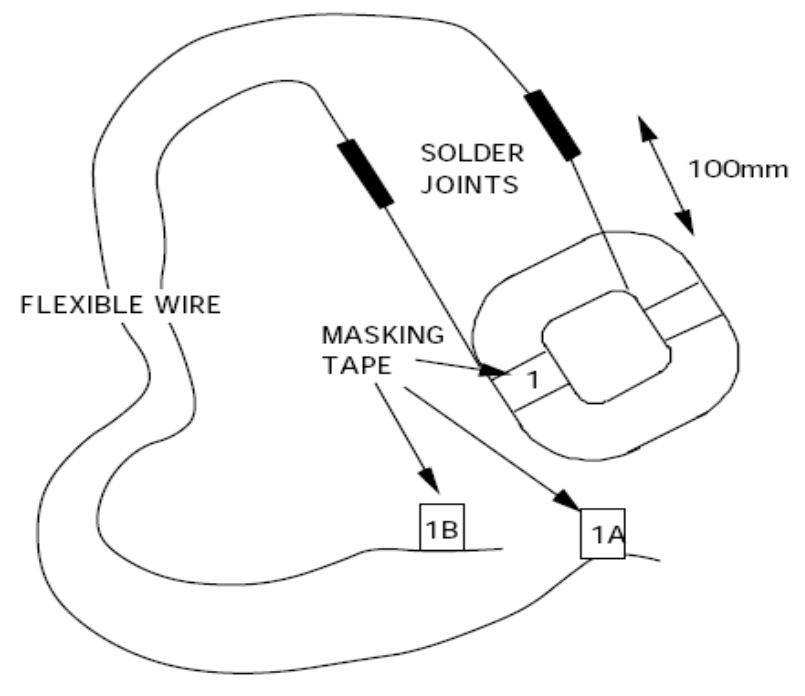

Figure 11: Soldering at tails of flex 
The images above demonstrate the assembly process of coil connections. The top figure shows the coil dimensions used for this design. There are twelve 1200 turns made up of copper wire coated in fiberglass resin. As per the middle figure, long wires are required for interconnection of the coils. The final figure depicts the importance of numbering each coil in order to avoid confusion in stator winding connections.

To achieve proper connection and optimum results, each coil's flexible tails should range in length between $800 \mathrm{~mm}$ to $1000 \mathrm{~mm}$. It is essential to ensure that every connection of the coils be soldered properly and insulate any open wires.

Numbering and color coding makes connection process quite easy. All coils should be numbered respectively. Each coil starting and ending points must be labeled, i.e. A for starting point and B for ending point. Keep the flexible tail wires long enough to connect coils at exit point on the stator disc.

\subsubsection{THE COILS IN THE MOULD}

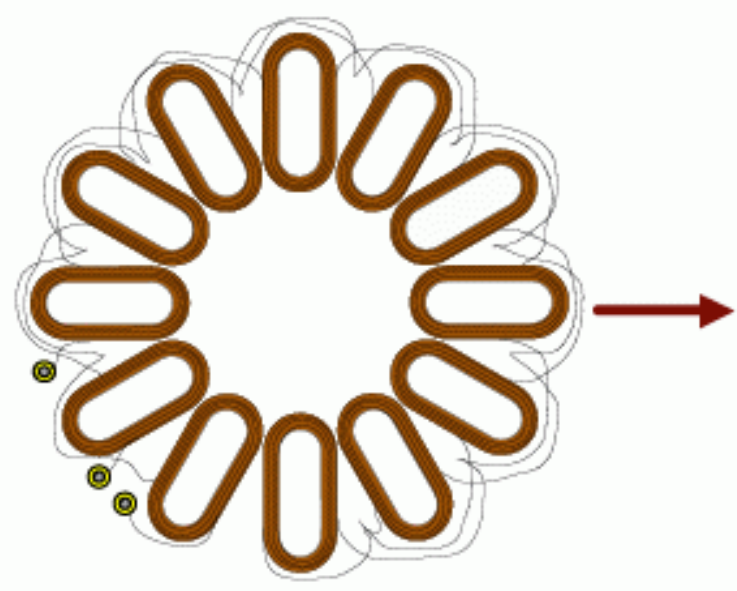

(a)

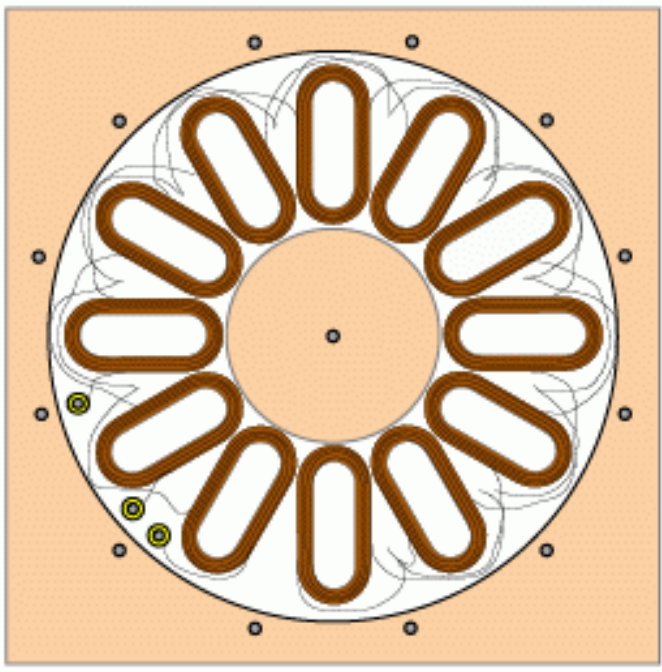




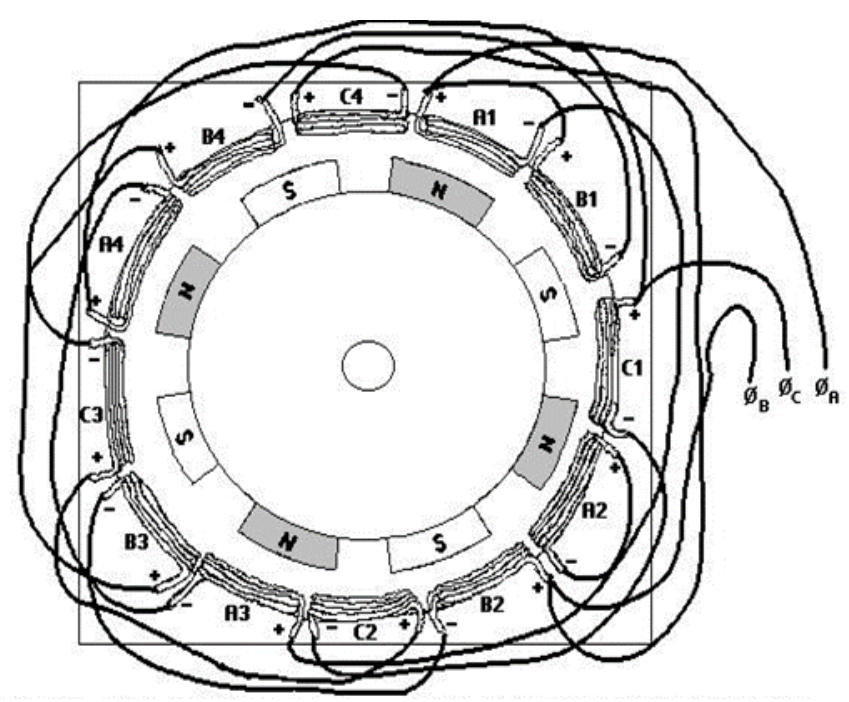

(b)

Figure 12: (a) and (b) Stator design

Above figures show the coil positioning on the stator disc. All coils are placed at equal distance, so twelve coils have to be place in 360 degree formation. Each coil is at thirty degrees from the neighboring coils. The center circle of the stator disc is to be cut out in order to connect the upper and lower magnet disc thru long studs through the stator. To achieve a balanced connection, four coils will be connected on each phase. The last figure displays the coil connection to attain three phase stator winding.

\subsection{ROTOR DESIGN}

The magnetic rotor is also a casting. It consists of magnet plates, magnet plates, magnet blocks, and stainless wire rope. Building a generator rotor requires rotor disc to be made up from steel, and it is important to note not to use stainless steel or aluminum for higher efficiency of the generator. In the generator, there are two magnetic rotors that are used. The stator is placed between two magnet rotors, and sixteen magnets are placed on each magnet rotors. The upper and lower rotors are connected with each other by long studs through the 
stator disc. The upper and lower rotor are connected to the center shaft, and this shaft is connected to the wind turbine blades directly.

\subsubsection{MAGNET BLOCKS}

Magnetic blocks used in this design are earth magnets. The dimensions of each magnet are $50 \mathrm{~mm} \times 50 \mathrm{~mm} \times 10 \mathrm{~mm}$. Neodymium magnets are one the common types of earth magnets, and this type of magnet is used in this model. These magnets are the most strongest and durable magnets available in the market. The neodymium magnets are the outcome of electrolytic boiling process of rare oxides from the earth.

The primary choice for magnets in this industry are neodymium magnets because they provide the maximum performance with minimum size. As these vertical axis wind turbines will be installed outdoors, and with the extreme temperatures of Canadian weather, the neodymium magnets provide the flexibility of withstanding in temperatures ranging between +150 degrees centigrade to -150 degrees centigrade, which no other magnetic counterpart has been able to provide.

The key characteristics of a neodymium magnet is that it contains high magnetic flux density. In addition, it offers better coercivity. It also has more saturation magnetization in comparison to others. Coating is a requirement in order to avoid oxidization. These magnets provide good performance through different temperature ranges. Lastly, and of more concern to manufacturing, the neodymium magnets offer the lowest price compared to other magnets with the same magnetic properties and capabilities. 


\subsubsection{THE MAGNET POSITIONING JIG}
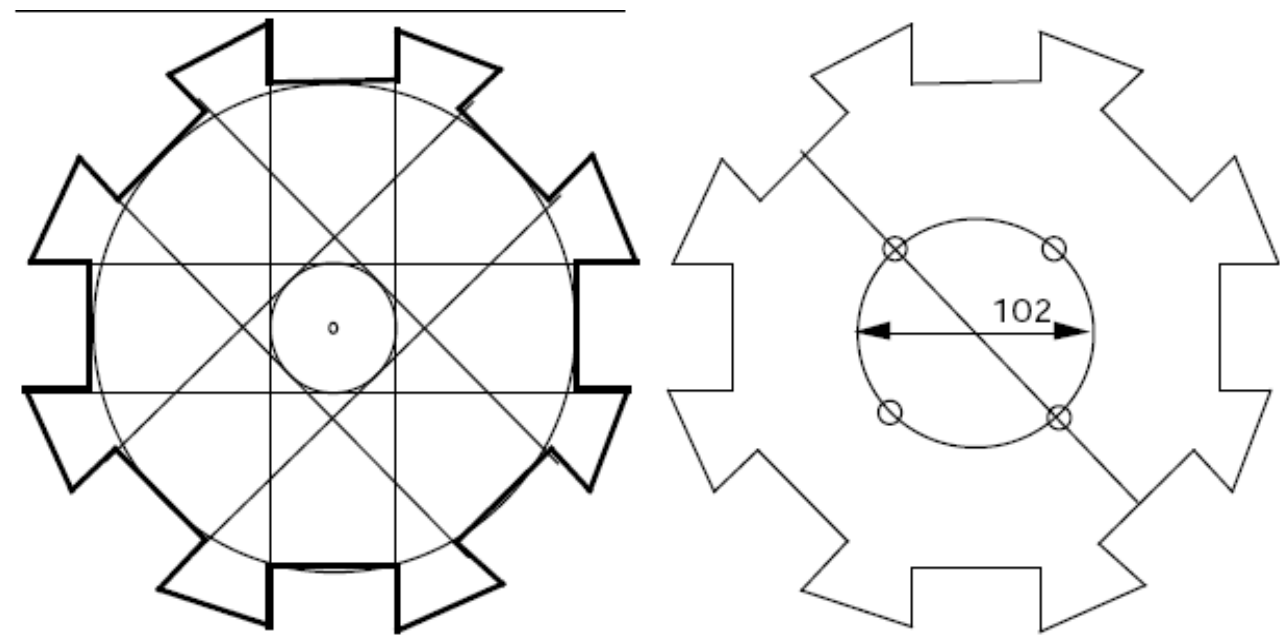

Figure 13: The magnet position jig

Steps to design magnetic jig for magnet rotor disc,

- Specify the center, illustrate three circles each having diameters $200 \mathrm{~mm} .102 \mathrm{~mm}$ and $50 \mathrm{~mm}$ on the center.

- As demonstrated in the figure below, illustrate tangents onto the $50 \mathrm{~mm}$ circle. At 45 degree and 90-degree angle, illustrate 3 straight-line pairs in reference to the original pair.

- Using the lines, indicate the magnetic positions. As demonstrated in the figure, cut and remove the jig that runs alongside the bold lines.

- In order to join the two opposing magnetic centers, illustrate a line. Put the PCD jig above the $102 \mathrm{~mm}$ circle. Ensure to align the PCD jig along the magnetic centers. Drill four holes in and align the holes within the steel disks. 


\subsubsection{MAGNET ROTOR DISK}

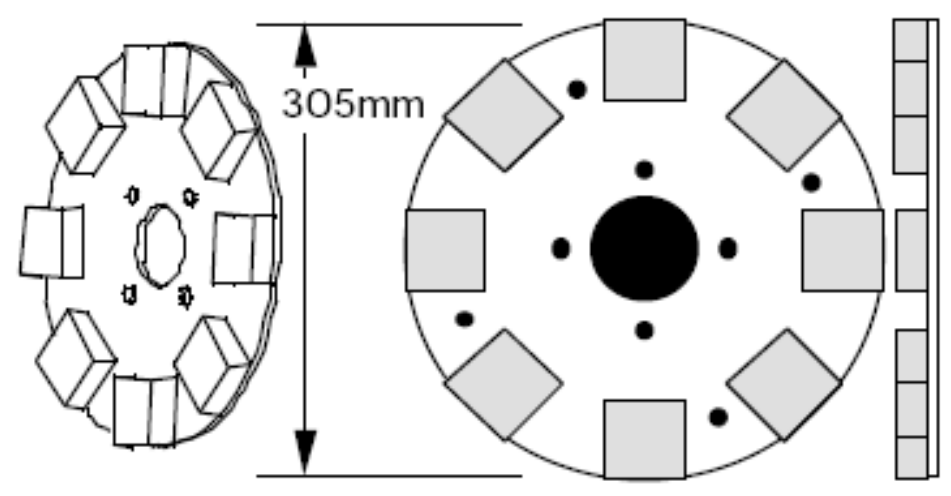

Figure 14: Magnet rotor disk

The leveling of the magnetic plates is required to be flat. Both magnet discs will be connected on shaft. The diameter of each magnet disc (plate) is $305 \mathrm{~mm}$. The best way to make the rotor disc is to first cut off circle (corners at 45 degrees) from square shaped plate.

\subsubsection{ALTERNATIVE SHAPE: AN OCTAGON}
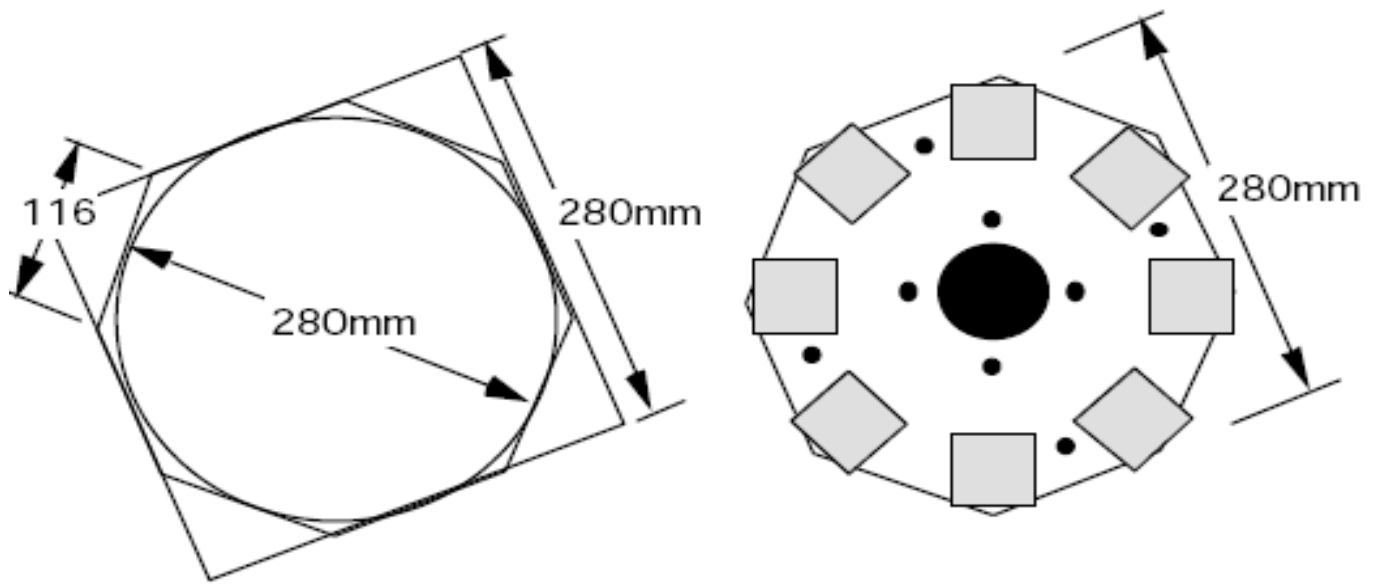

Figure 15: Position of magnet

Alternative method to cut magnet rotor disk is shown in figure above. Cut off circle corners at 45 degrees from square plate. The central hole is cut out on a lathe machine. It is 
important to ensure to grind the disks (made of steel) until the disks are clean and bright, prior to laying the disks in mould for resin coating. Each rotor consists of 16 magnetic blocks, and every single block contains a north pole as well as a south pole.

\subsubsection{POLES ON THE MAGNET BLOCKS}

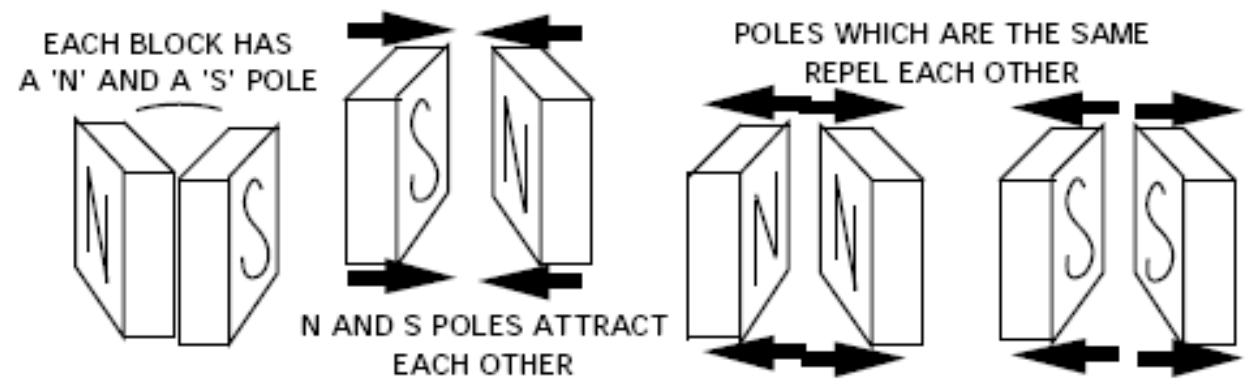

Figure 16: Checking Magnet polarities

Magnetism of these magnets are really strong, so they can break if they come in contact with each other so it is important to take the appropriate precautions. Slides magnets sideways in order to separate the magnets from each other. It is evident to ensure that the magnets to not pull towards each other as there is a serious risk of the magnets breaking. It is important to remember to never use a hammer or such dangerous tools to construct the PMG, as there is a possibility of breaking the resin or the magnet.

It is important that the upper face of the magnet blocks located on the disk must have an alternation of N-S-N-S. In order to reassure that the procedure is being conducted correctly, a technique is available to check. Before placing the magnetic block, ensure to hold the block close to the previous block to allow them to repel, and then situate the block without having to turn it. One by one, place all magnets on magnet rotor disc. After placing all magnets, check 
with another magnet: pass magnet through each magnet one by one and magnet in your hand will be attracted, repelled, attracted and repelled respectively.
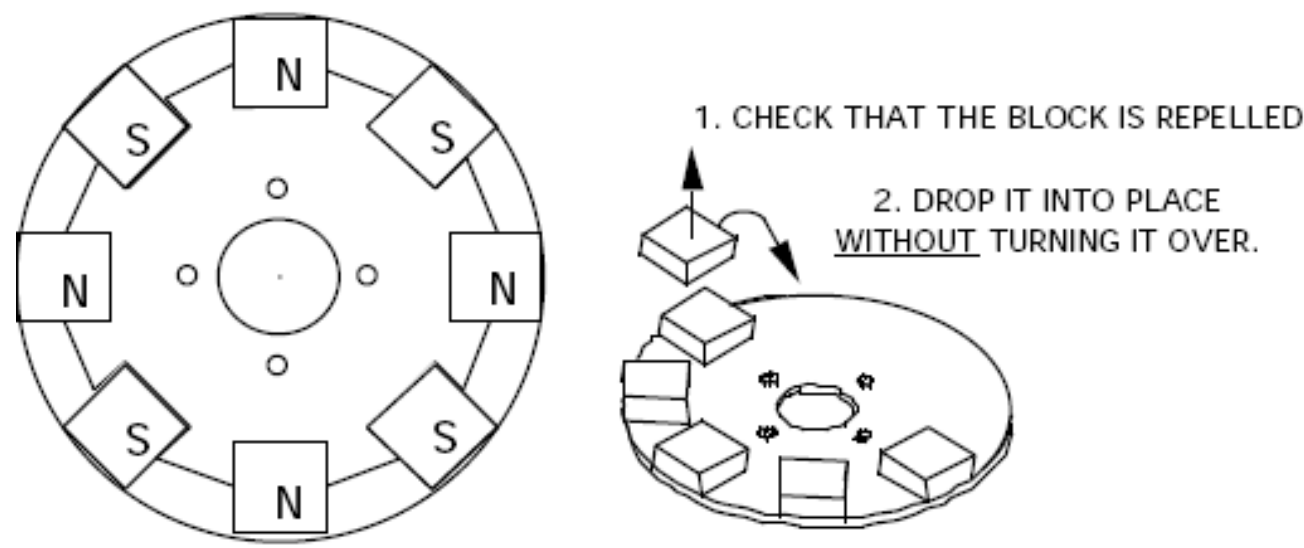

Figure 17: PLACING THE MAGNET BLOCKS
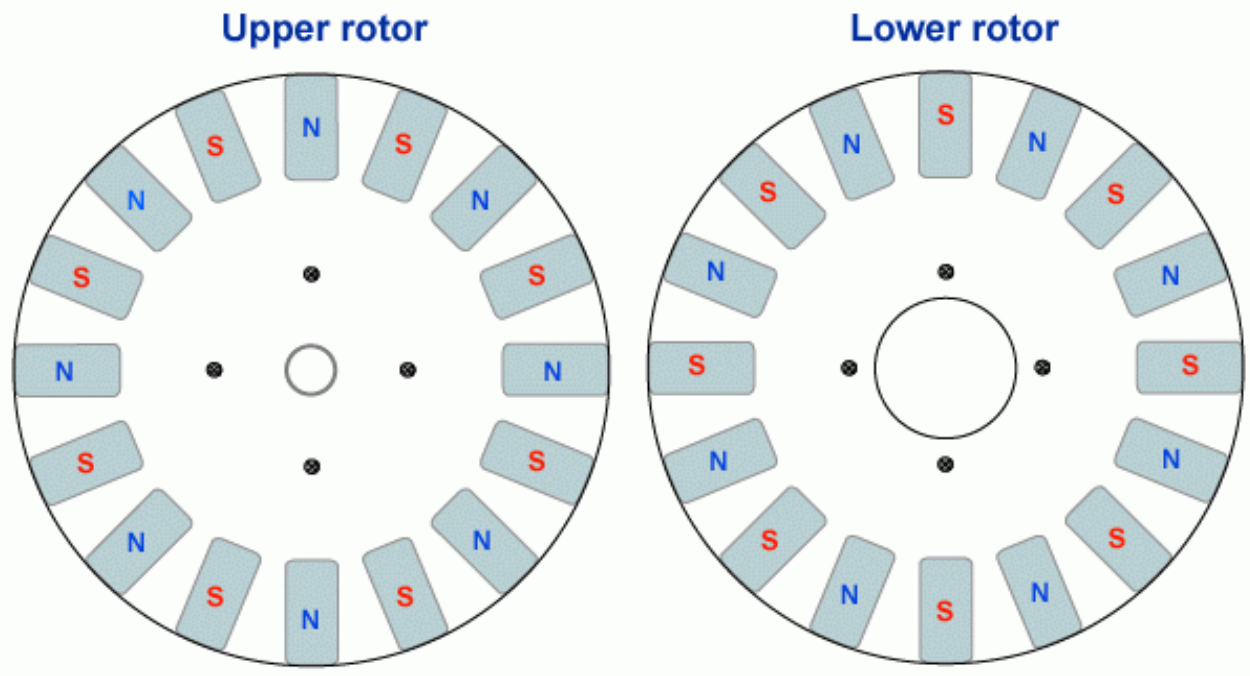

Figure 18: Complete Upper and Lower Magnet rotors

Figure shows the how to place magnets and Upper - Lower magnet rotors. 32 magnets $(50 \mathrm{~mm} \times 50 \mathrm{~mm} \times 10 \mathrm{~mm})$ are used here. Both rotors are connected by steel bars or long strong screws through stator. Complete generator assembly shown below. 


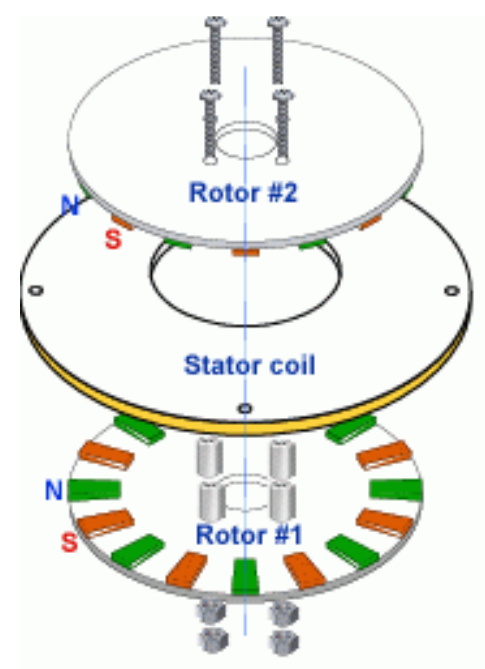

Figure 19: Complete PM generator Assembly.

Figure shows the Upper magnet rotor, Lower magnet rotor and Stator disc. Both rotors are connected to VAWT blades through shaft. Blades will rotate both rotor will and stator coils will cut magnetic lines of force, which will produce electricity. 


\section{6- CONVERTER SYSTEM}

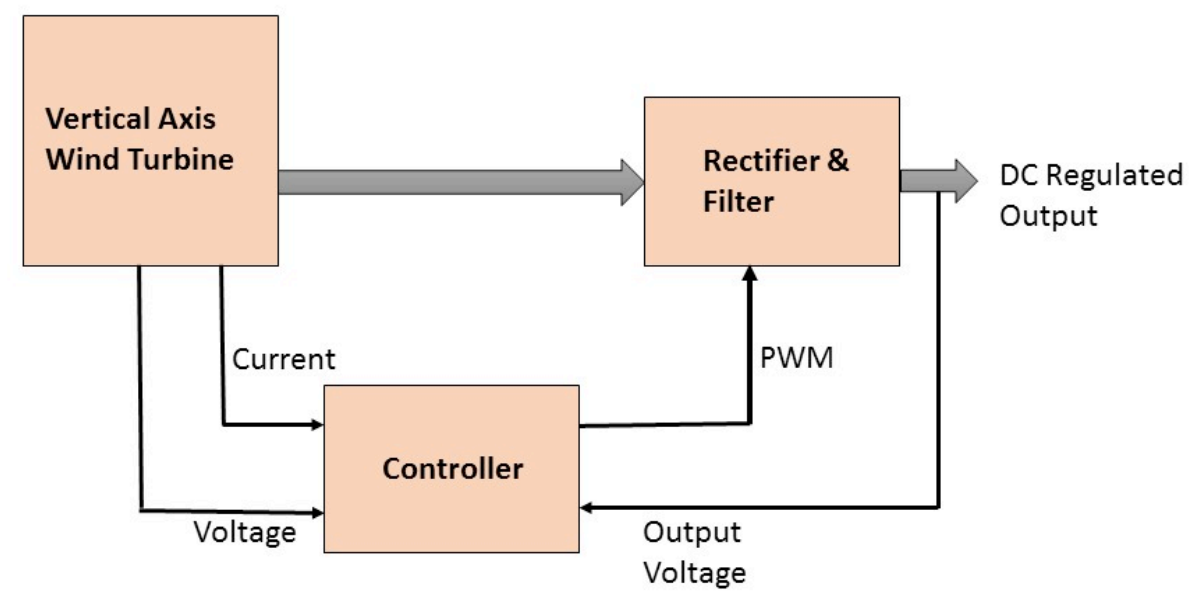

Figure 20: Converter System block diagram.

Figure shows the converter system block diagram. Main components of this system are,

- $\quad$ Rectifier \& Filter circuit

- Controller circuit

Rectifier is a device, which converts alternating input voltage to pulsating DC voltage. Three-phase PWM reversible rectifier topology is used to convert variable AC to regulated DC output. The most important goal of this converter system is power quality and protection. This converter system also gives protection from load side overcurrent fault by limiting line current's amplitude. That process diereses the copper losses and improves power factor of the system. Combining numerous VAWTs on one converter system can provide optimum results in terms power generation. 


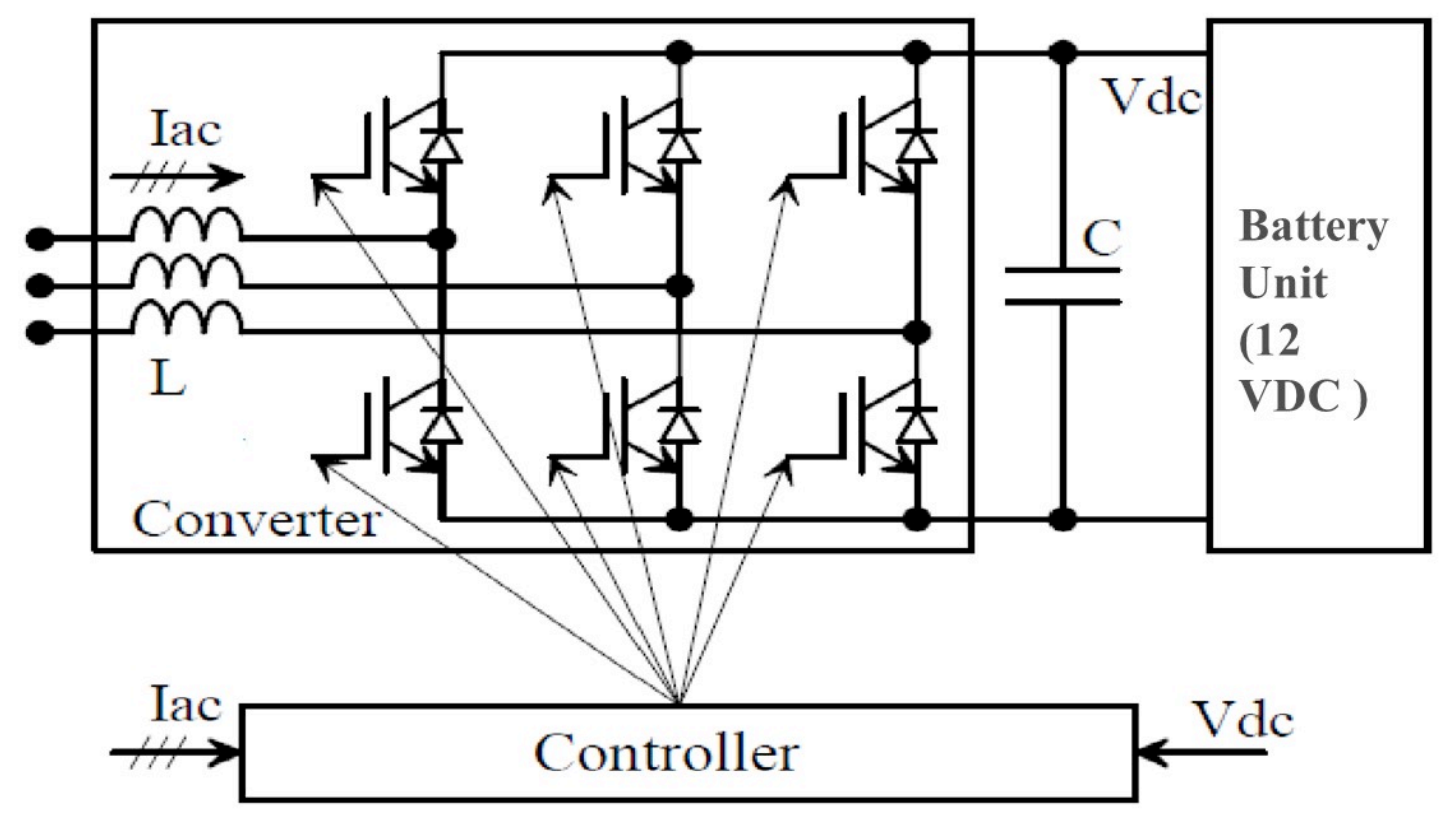

Figure 21: Circuit model of the 3phase PWM rectifier

Above figure shows the rectifier, filter and controller optimized for this design. It consists of Pulse Width Modulation rectifier, capacitor and battery unit. Vertical axis wind turbine supplies generate 3phase power (variable voltage, current and frequency). Inductor L is used here to provide current feedback to controller and Capacitor $\mathrm{C}$ is used here to provide voltage feedback to controller. The main goal of this converter system is to supply constant $12 \mathrm{~V} \mathrm{DC}$ to battery unit. Another important task is to achieve sinusoidal wave shape for generated current and also make generated current and voltage in phase with each other. 


\section{7- CALCULATIONS}

The objective of this project is to design a permanent magnet generator for VAWT. Rated wind speed for this turbine is $7 \mathrm{~m} / \mathrm{s}$. Radius of wind turbine is $0.9 \mathrm{~m}$. Total height of turbine's blade is $1.3 \mathrm{~m}$. Maximum flux density $B_{\max }$ is 1.62 .

\section{RAYLEIGH DISTRIBUTION}

Wind speed fluctuates all around the year. One of the key elements of wind turbine design is availability of wind at wind turbine installation place. It is really necessary to predict and measure wind profile of that place. Rayleigh distribution model is most adoptive model for wind farm design. This model is presented by,s

$$
p(v)=\frac{\pi}{2} \times\left(\frac{v}{\bar{v}^{2}}\right) e^{-\frac{\pi}{4}\left(\frac{v}{\bar{v}}\right)^{2}}
$$

Where,

$v=$ Wind Speed in $\mathrm{m} / \mathrm{s}$,

$\bar{v}=$ Mean value of Wind speed $\mathrm{m} / \mathrm{s}$,

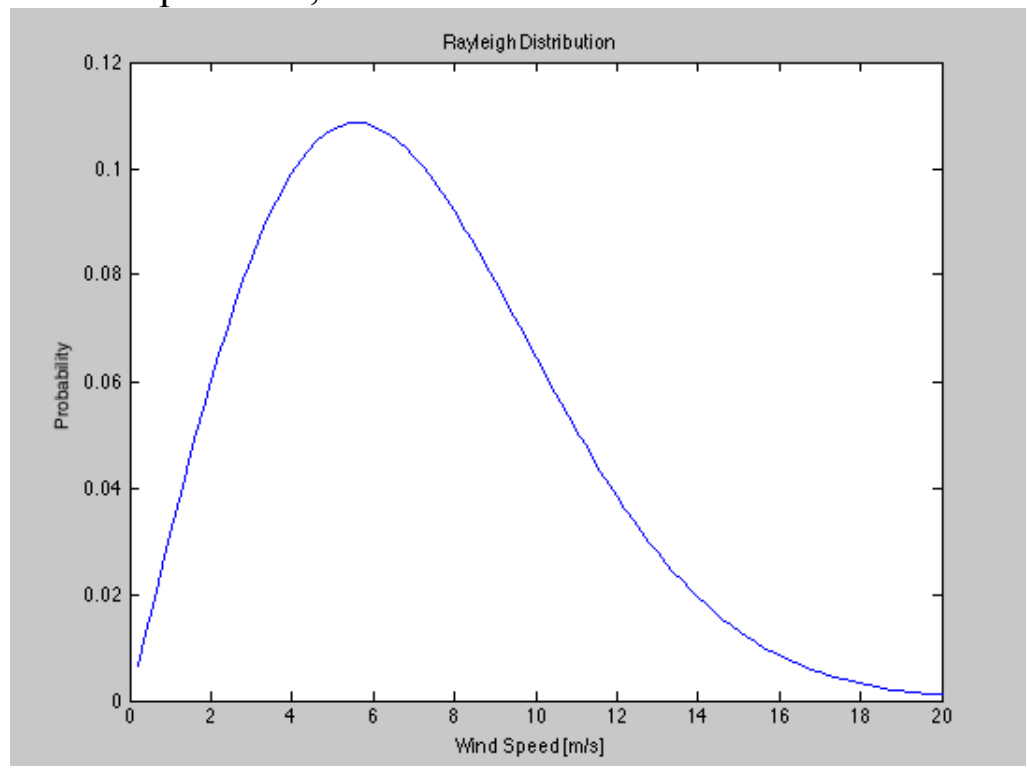

Figure 22: Rayleigh distribution - Probability of Wind Power 


\subsection{The Wind Power}

Wind's air molecule mass movement generates kinetic energy in wind, which can calculate by,

$$
\text { Kinetic Energy }=\frac{1}{2} \times \text { Mass } \times v^{2}
$$

Since the mass of the air is equal to the area multiplied by velocity and density. Power of wind can be calculated using kinetic energy and mass of air equations,

$$
\text { Power }=\frac{1}{2} \times \text { Area } \times \rho \times v^{3}
$$

In practical practices, $100 \%$ energy transfer from wind to wind turbine rotor is not possible. The loss of energy can be considered in the equations by considering power coefficient value. Wind power equation becomes,

$$
\begin{gathered}
P_{\text {wind }}=\frac{1}{2} \times C_{p} \rho A_{t} v^{3} \\
P_{\text {wind }}=\frac{1}{2} \times 0.52 \times 1.225 \times \pi \times 1.3 \times 0.9 \times 7^{3} \\
=401.55
\end{gathered}
$$

Where, $C_{p}=$ Coefficient of Power

$\rho=$ Air Density

$A_{t}=$ Cross sectional area of the turbine $=\pi r h$ (for Vertical Axis Wind Turbine) 


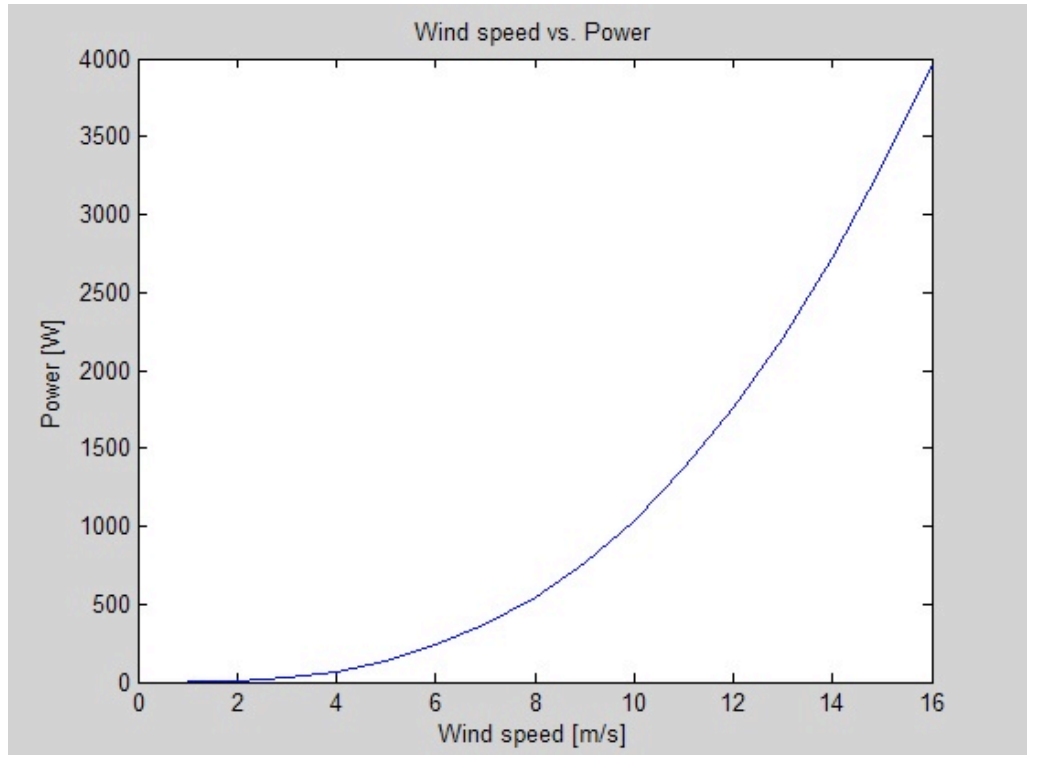

Figure 23: Wind speed vs Wind Power

Figure shows behavior plot, plot between wind speed and power. From the plot we can say that Wind power increases with an increase in wind speed. Practical plot of Wind Speed vs Wind Power plot for VAWT is different than this plot.

\section{Behavior Plot}

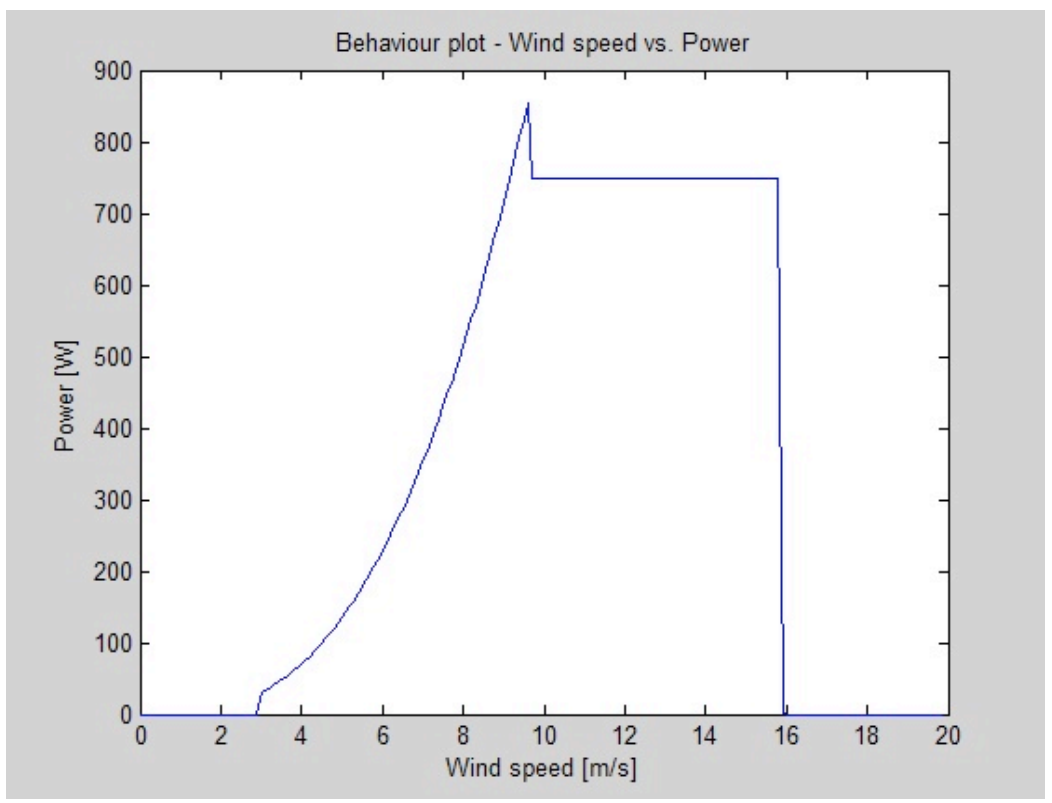

Figure 24: Wind speed Vs Power 
Figure shows behavior plot, plot between wind speed and power. From the plot we can see that cut in speed $(3 \mathrm{~m} / \mathrm{s})$ and cutout speed $(16 \mathrm{~m} / \mathrm{s})$ is achieved. Plot between wind speed and power from calculated values (for same parameters) is different than this plot. This plot is an actual practical plot of Wind Speed vs Wind Power so it is called Behavior plot.

\subsection{Generator Induced Voltage \& Current}

\section{Angular frequency $\left(w_{\text {mech }}\right)$}

Angular frequency is related to wind speed of the wind turbine,

$$
\begin{gathered}
w_{\text {mech }}=T S R \times \frac{v}{r} \\
w_{\text {mech }}=0.5 \times \frac{7}{0.9} \\
=3.89 \mathrm{rad} / \mathrm{sec}
\end{gathered}
$$

Where,

$r=$ radius of the turbine

$v=$ wind velocity

\section{Pitch Factor}

Pitch factor is measure of difference between induced voltage in short pitched and full piched coil. When machine doesn't have q=1, there will be losses in magnetic flux and this will result in decrease in the induced voltage.

$$
\begin{gathered}
k_{p}=\sin \left(\frac{180 P n}{2 Q}\right) \\
=0.9945
\end{gathered}
$$




\section{Distribution Factor}

Distribution factor is ratio between phasor sum of the induced emf in stator winding to the arithmetic sum the induced emf in stator winding. This factor also results in reduction of induced voltage.

$$
\begin{aligned}
k_{d} & =\frac{\sin \left(q \frac{\alpha}{2}\right)}{q \times \sin \left(\frac{\alpha}{2}\right)} \\
& =0.9834
\end{aligned}
$$

\section{Winding Factor}

Winding factor is product of pitch factor and distribution factor.

$$
\begin{aligned}
k_{w} & =k_{d} k_{p} \\
& =0.9834 \times 0.9945 \\
& =0.9780
\end{aligned}
$$

\section{Mechanical and electrical frequency}

$$
\begin{gathered}
f_{\text {mech }}=\frac{w_{\text {mech }}}{2 \pi} \\
=0.619 \mathrm{rad} / \mathrm{sec} \\
f_{\text {elec }}=\frac{w_{\text {mech }}}{4 \pi} \times p \\
=9.90 \mathrm{hz}
\end{gathered}
$$

Where,

$f_{\text {mech }}=$ mechanical frequency

$f_{\text {elec }}=$ electrical frequency, frequency of induced voltage 
$w_{\text {mech }}=$ angular frequency

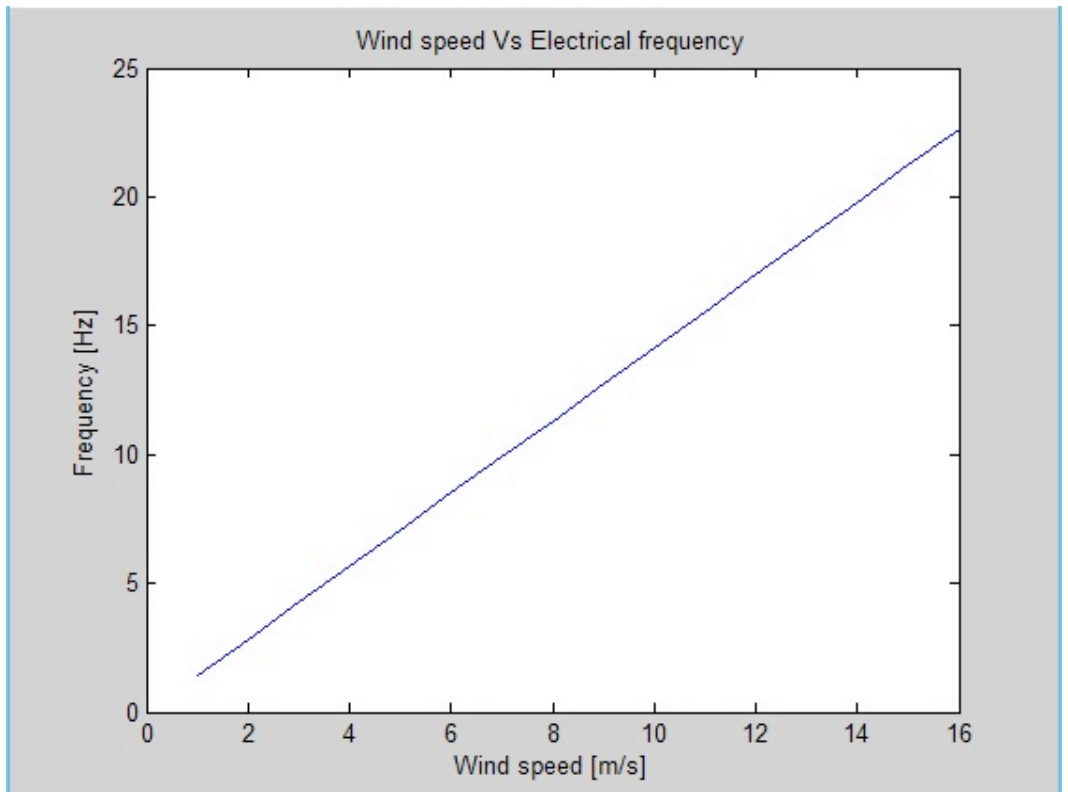

Figure 25: Plot for Wind speed vs Electrical Frequency

Figure shows plot between wind speed and electrical frequency. From the plot we can see that frequency is directly proportional to wind speed, it changes linearly with the wind speed.

\section{Induced Phase Voltage}

$$
\begin{gathered}
E_{L N}=\sqrt{2} \pi f_{\text {elec }} n \phi k_{w} \\
E_{L N}=\sqrt{2} \pi \times 9.90 \times 120 \times 0.0026 \times 0.978 \\
=13.61 \mathrm{~V}
\end{gathered}
$$

Where,

$\mathrm{E}=$ Induced phase voltage

$k_{w}=$ Winding factor

$f_{\text {elec }}=$ Electrical frequency, frequency of induced voltage 
$\mathrm{n}=$ Number of conductor per phase in stator

$\phi=$ Magnetic flux

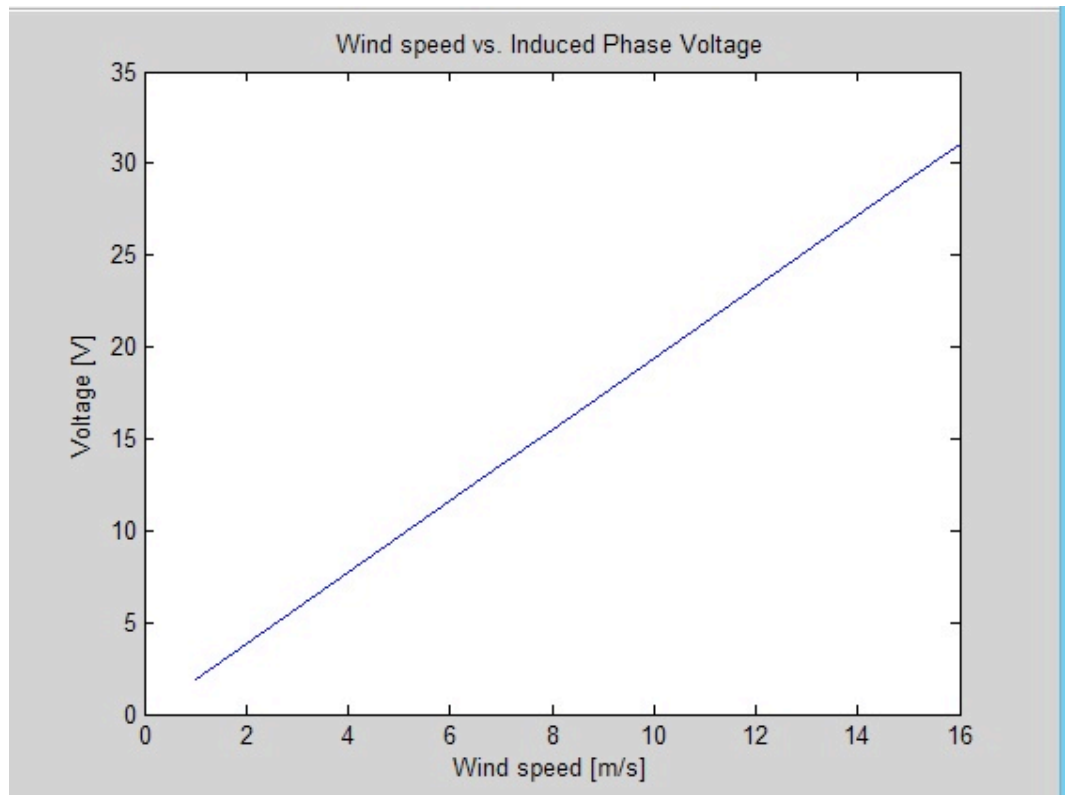

Figure 26: Plot for Wind speed vs Induced phase Voltage

Figure shows plot between wind speed and Induces phase voltage. From plot we can say that Induced phase voltages are directly proportional to wind speed, it changes linearly with it.

\section{Induced Line Voltage}

$$
\begin{gathered}
E_{L L}=\sqrt{3} E_{L N} \\
=23.57 \mathrm{~V}
\end{gathered}
$$




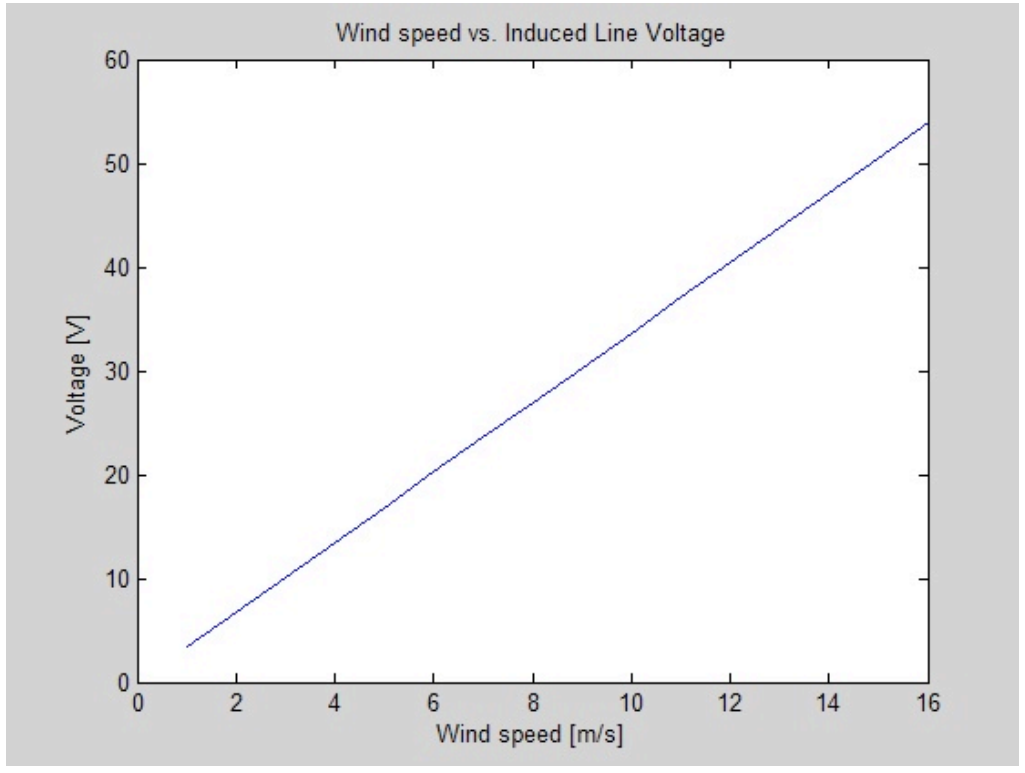

Figure 27: Plot for Wind speed vs Induced Line Voltage

Figure shows plot between wind speed and Induces Line voltage. From plot we can say that Induced line voltages are directly proportional to wind speed, it changes linearly with it.

\section{Current}

Rated current in the generator is calculated using equation below,

$$
\begin{aligned}
& I=\frac{P}{3 \times E_{L N}} \\
& =\frac{401.55}{3 \times 13.61} \\
& =9.83 \mathrm{Amp}
\end{aligned}
$$




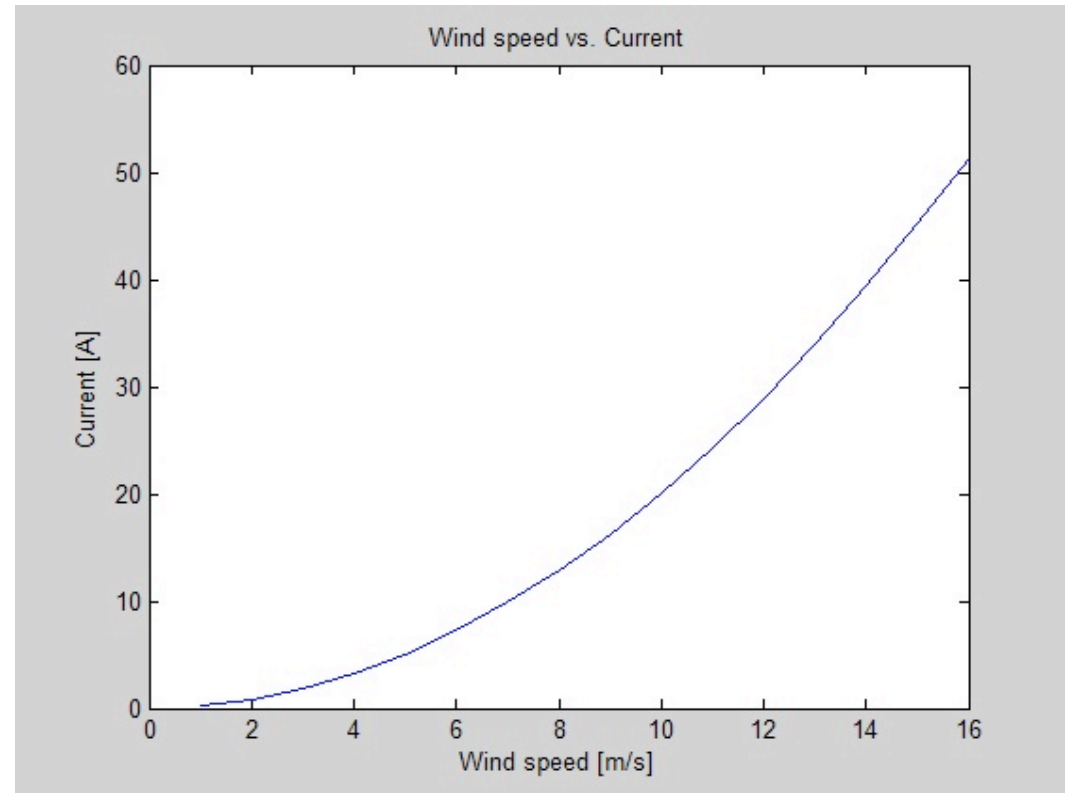

Figure 28: Plot for Wind speed Vs Current

Figure shows plot between wind speed and generator current. From plot we can see that current is directly proportional to wind speed, it increases with increase in wind speed.

\subsection{GENERATOR LOSSES AND EFFICIENCY}

There are two types of losses in generator, one is mechanical losses and another is electromagnetic losses. Electromagnetic losses include copper losses and iron losses. The resistive losses depends upon the inner resistance of the conductor,

$$
R_{\text {inn }}=0.1037 \Omega
$$

\section{Copper Losses:}

Whenever current passing through a conductor, it produces heat that is called copper losses. Heat production or copper losses is dependent upon resistivity and current carrying capacity of wire or conductor.

$$
P_{\text {losses }}^{\text {Cu }}=3 R I^{2}=3 \times 0.1037 \times 9.83^{2}
$$




$$
=30.09 \mathrm{~W}
$$

\section{Iron losses:}

Iron loss is due to stray eddy current, so it is depend upon magnetic flux.

$$
\begin{aligned}
P_{\text {losses }}^{F e}=k_{h} B_{\text {max }}^{2} f_{\text {elec }} & +k_{c} B_{\text {max }}^{2} f_{\text {elec }}^{2}+k_{e} B_{\text {max }}^{3 / 2} f_{\text {elec }}^{3 / 2} \\
& =3.26 \mathrm{~W}
\end{aligned}
$$

Where,

$\mathrm{I}=$ generated Current.

$B_{\max }=$ Maximum magnetic flux density.

$$
k_{c}=\frac{\pi^{2} \sigma d^{2}}{6 \rho m}=9.77 \times 10^{-5}
$$

The total losses,

$$
\begin{aligned}
P_{\text {losses }}^{\text {total }} & =P_{\text {losses }}^{\text {Cu }}+P_{\text {losses }}^{F e} \\
& =33.35 \mathrm{~W}
\end{aligned}
$$

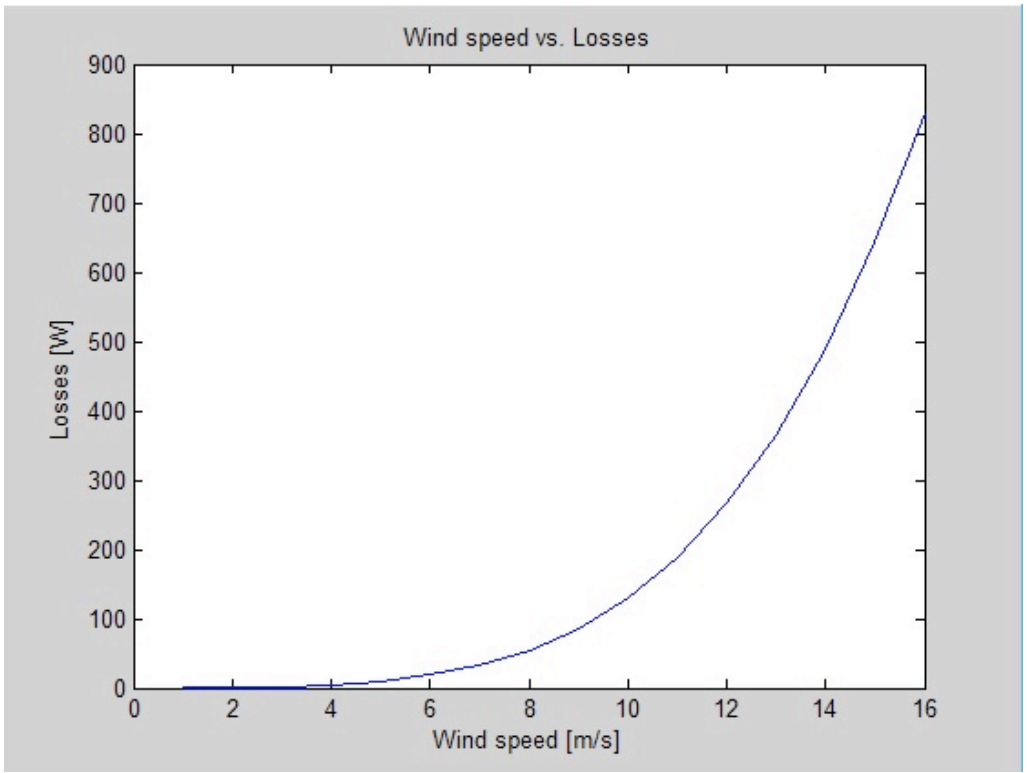

Figure 29: Plot for Wind speed Vs Total Losses 
Figure shows plot between wind speed and generator losses. From plot we can see that losses are directly proportional to wind speed, losses increases with increase in wind speed.

\section{Generator Terminal Power (W),}

$$
\begin{aligned}
P_{t}= & P_{\text {wind }}-P_{\text {losses }}^{\text {total }} \\
& =401.55-33.35=368.19 \mathrm{~W}
\end{aligned}
$$

The efficiency of the generator,

$$
\begin{gathered}
\eta=\frac{P}{P+P_{\text {losses }}^{\text {total }}}=\frac{368.19}{368.19+33.355} \\
=91.7 \%
\end{gathered}
$$

Table 3 -Calculation for electrical power output, No of Hours/year, Annual Energy generated at various wind velocities

\begin{tabular}{|c|c|c|c|c|c|}
\hline $\begin{array}{c}\text { Wind } \\
\text { Speed } \\
\text { (m/s) }\end{array}$ & $\begin{array}{c}\text { Wind } \\
\text { Power (W) }\end{array}$ & $\begin{array}{c}\text { Genrator } \\
\text { Terminal } \\
\text { Power } \\
\text { (W) }\end{array}$ & $\begin{array}{c}\text { Rayleigh } \\
\text { Wind } \\
\text { Probability }\end{array}$ & $\begin{array}{c}\text { No of } \\
\text { Hours / } \\
\text { Year (hrs) }\end{array}$ & $\begin{array}{c}\text { Annual } \\
\text { Energy } \\
\text { generated } \\
\text { (Wh) }\end{array}$ \\
\hline 1 & 1.17 & 0.81 & 0.015 & 131 & 0 \\
\hline 2 & 9.37 & 8.41 & 0.021 & 184 & 0 \\
\hline 3 & 31.61 & 29.39 & 0.031 & 272 & 7982.23 \\
\hline 4 & 74.92 & 70.04 & 0.06063 & 531 & 37200.79 \\
\hline 5 & 146.34 & 136.33 & 0.0832 & 729 & 99359.45 \\
\hline 6 & 252.87 & 233.92 & 0.0992 & 869 & 203275.05 \\
\hline 7 & 401.55 & 368.19 & 0.1073 & 940 & 346083.42 \\
\hline 8 & 599.40 & 544.22 & 0.108 & 946 & 514873.97 \\
\hline
\end{tabular}




\begin{tabular}{|c|c|c|c|c|c|}
\hline 9 & 853.44 & 766.76 & 0.1047 & 917 & 703252.23 \\
\hline 10 & 1170.70 & 1040.29 & 0.092 & 806 & 838392.41 \\
\hline 11 & 1558.20 & 1368.98 & 0.0787 & 689 & 943789.70 \\
\hline 12 & 2022.97 & 1756.68 & 0.0641 & 562 & 986406.21 \\
\hline 13 & 2572.03 & 2206.98 & 0.0477 & 418 & 922189.61 \\
\hline 14 & 3212.40 & 2723.12 & 0.0382 & 335 & 911243.11 \\
\hline 15 & 3951.11 & 3308.08 & 0.0227 & 199 & 657817.91 \\
\hline 16 & 4795.18 & 3964.51 & 0.0192 & 168 & 666799.3854 \\
\hline$\geq 17$ & \multicolumn{5}{|c|}{ Annual Saving } \\
\hline \multicolumn{7}{|c|}{0.00737} & 65 & 0 \\
\hline \multicolumn{7}{|c|}{} & & & $\$, 838,665.48$ \\
\hline
\end{tabular}

Table shows the complete over view of vertical axis wind turbine's important parameters. Table shows the Wind power and Generator terminal power at different wind speeds. This turbine is designed to work for $3 \mathrm{~m} / \mathrm{s}$ to $16 \mathrm{~m} / \mathrm{s}$ wind speed. Rayleigh wind probability of mounting area give us probability of wind throughout the month or year. From wind availability (no of hours), we can get annual energy generated. Total annual energy generation will be 7,838.665.48 wh. In Ontario wind power price is $\$ 0.108$ per $\mathrm{kWh}$, so we can save $\$ 8465.76$ annually by this wind turbine. 


\section{8-SIMULATION OF VERTICAL AXIS WIND TURBINE}

\subsection{SIMULATION MODELING}

MATLAB Simulation tool was used to make Vertical Axis Wind Turbine model. VAWT model important subsystems are,

- Power Co-efficient $\left(C_{p}\right)$ sub-system.

- $\quad$ Tip speed Ratio $(\lambda)$ sub-system.

- Mechanical Power sub-system.

- Permanent magnet generator sub-system.

\section{Power Coefficient (Cp) sub-system}

Power Co-efficient is amount of energy that can be taken from the wind. $C_{p}$ is simulated using equation written below,

$$
C_{p}=C_{1}\left(\frac{C_{2}}{\lambda_{1}}-C_{3} \beta-C_{4}\right) e^{-\frac{C_{5}}{\lambda_{1}}}+C_{6} \lambda
$$

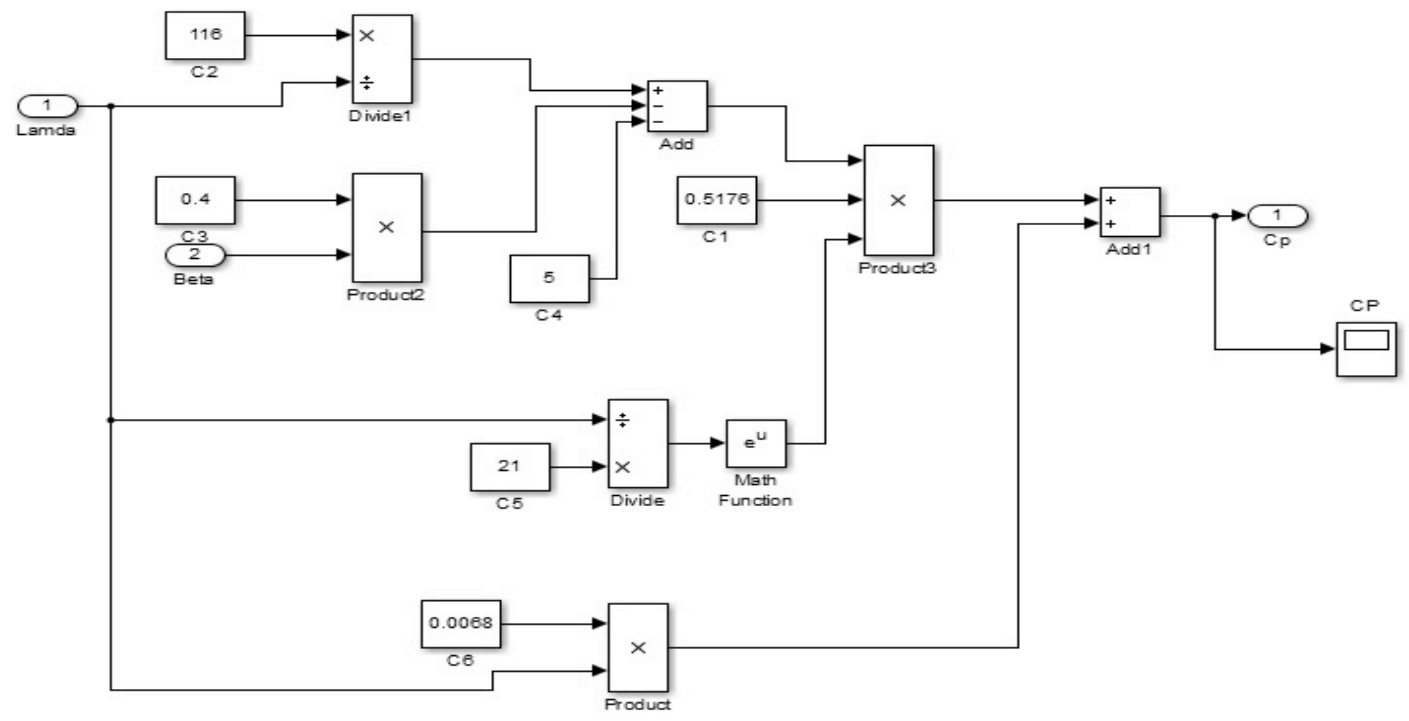

Figure 30: Simulation model for Power Coefficient 


\section{Tip speed ratio $(\lambda)$ sub-system}

TSR syb-system is simulated using equation written below,

$$
\lambda=\frac{R \times w}{v}
$$

Where

$v=$ wind speed

$w=$ turbine speed.

\section{Mechanical Torque or Power Sub-system (VAWT sub-system)}

Mechanical power sub-system is designed using equation written below,

$$
P_{\text {mech }}=\frac{1}{2} \times C_{p} \rho A_{t} v^{3}
$$

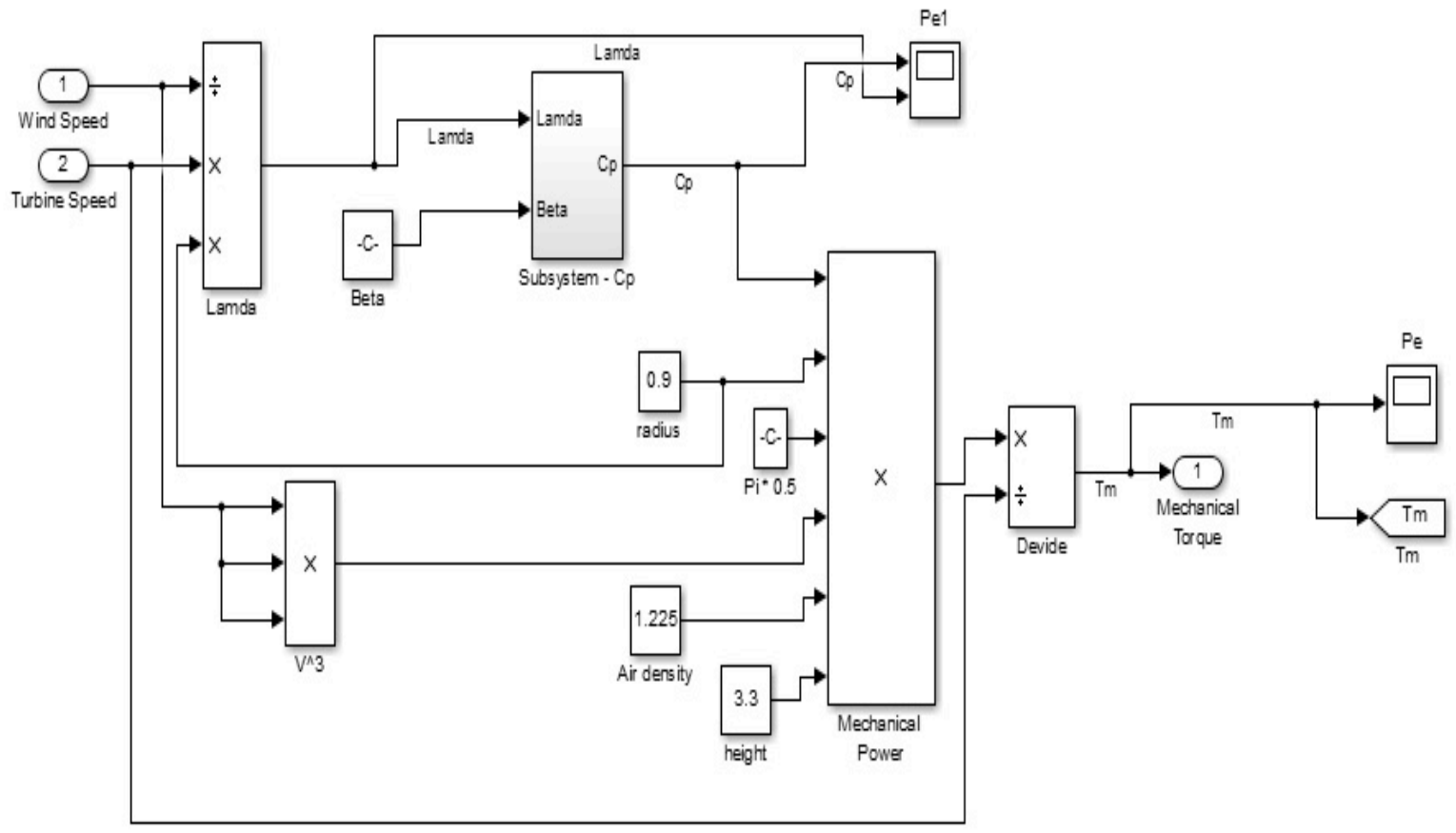

Figure 31: Simulation model for Mechanical power sub-system 


\section{Permanent magnet generator sub-system}

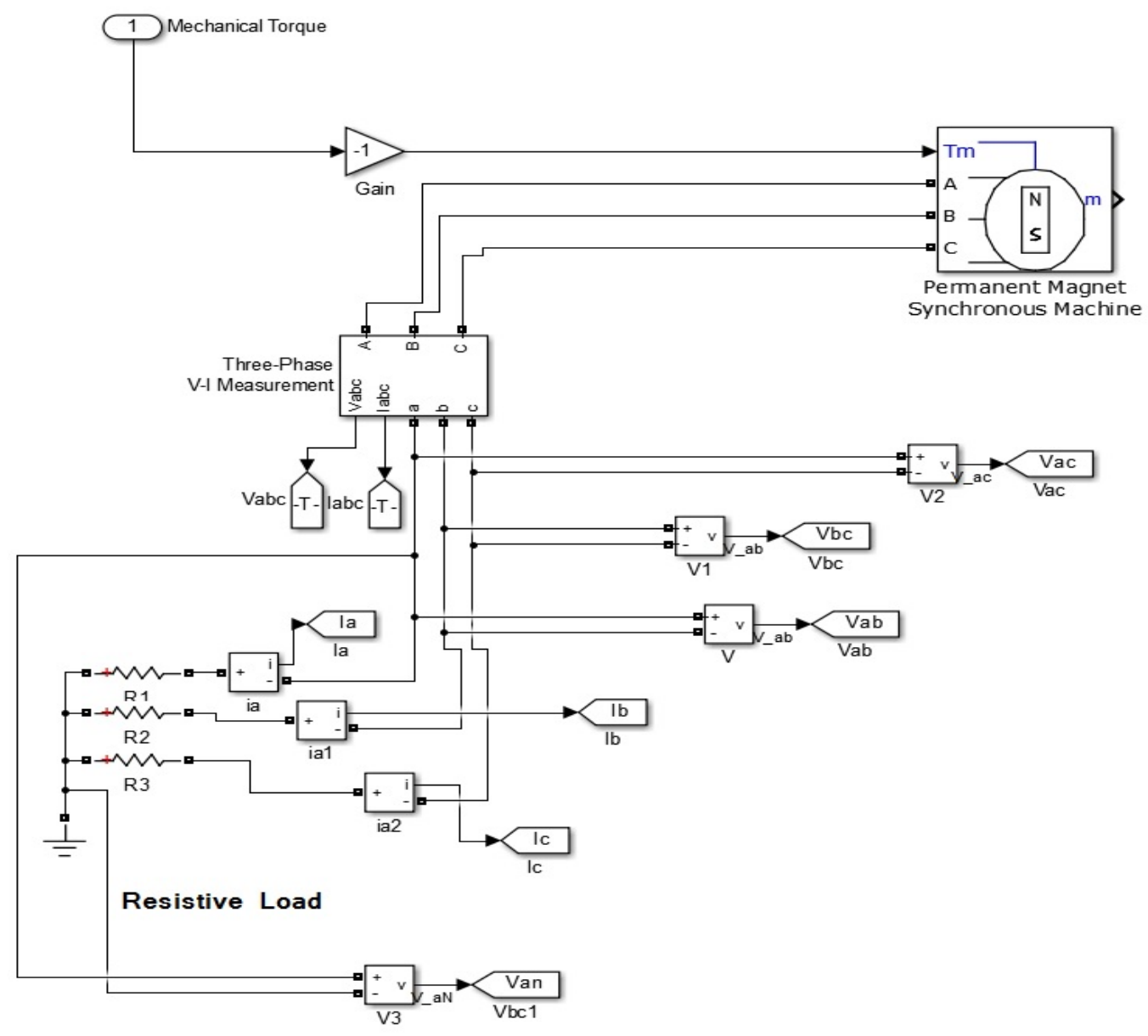

Figure 32: Simulation model of PM generator sub-system

Above figure shows the simulation model of PM generator for VAWT. Mechanical torque was supplied as input from Mechanical power sub-system. Generator requires negative torque. 


\subsection{SIMULATION RESULTS}

Vertical Axis Wind Turbine simulation model was developed considering design parameters. Simulation results are examined for design improvements.

\section{Mechanical Toque}

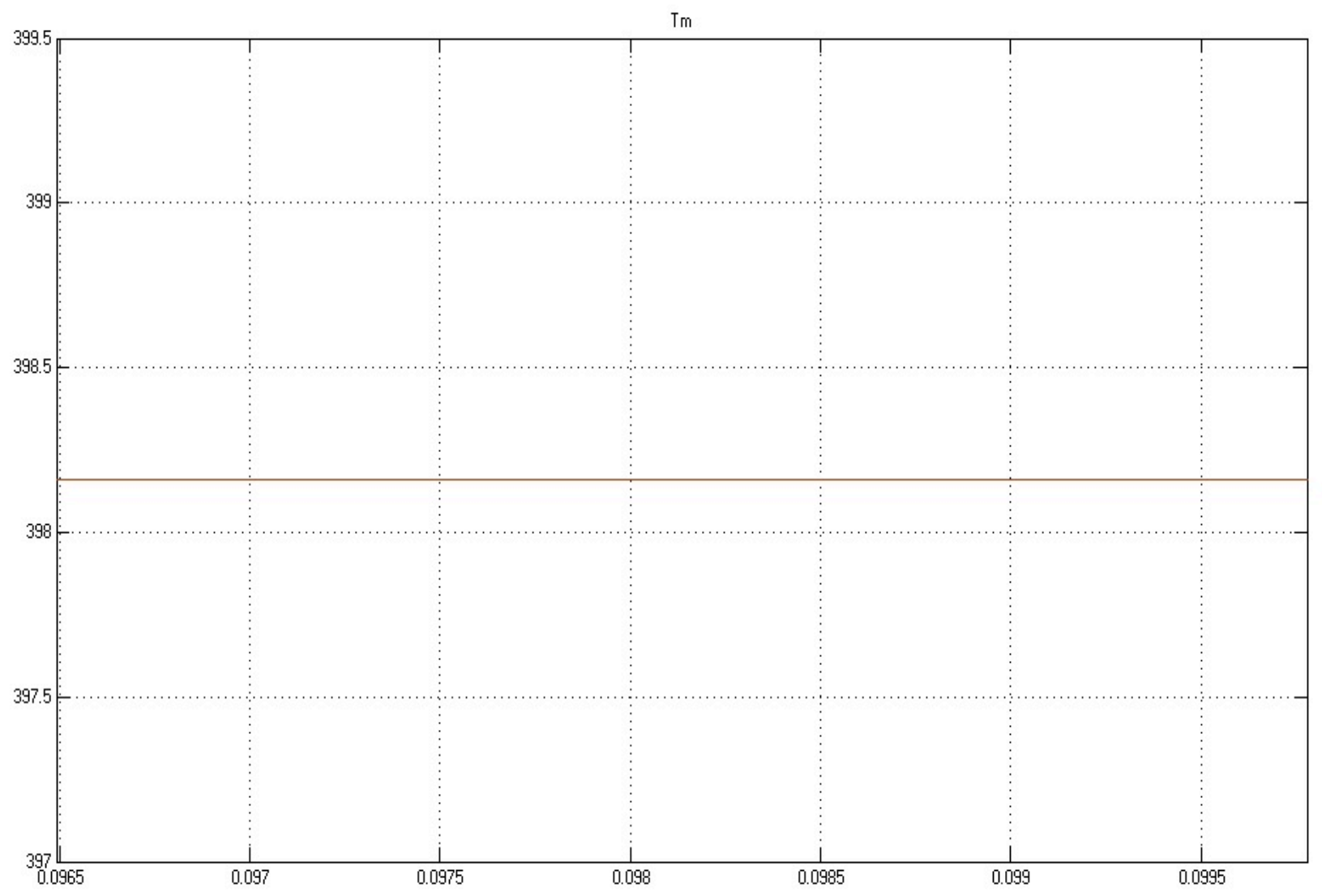

Figure 33: Mechanical Torque

Figure shows the mechanical torque produced by VAWT's Mechanical power subsystem. Mechanical torque produced is $398 \mathrm{Nm}$. This generated torque is supplied to PM generator for electricity production. 


\section{Induced Phase \& Line Voltage}
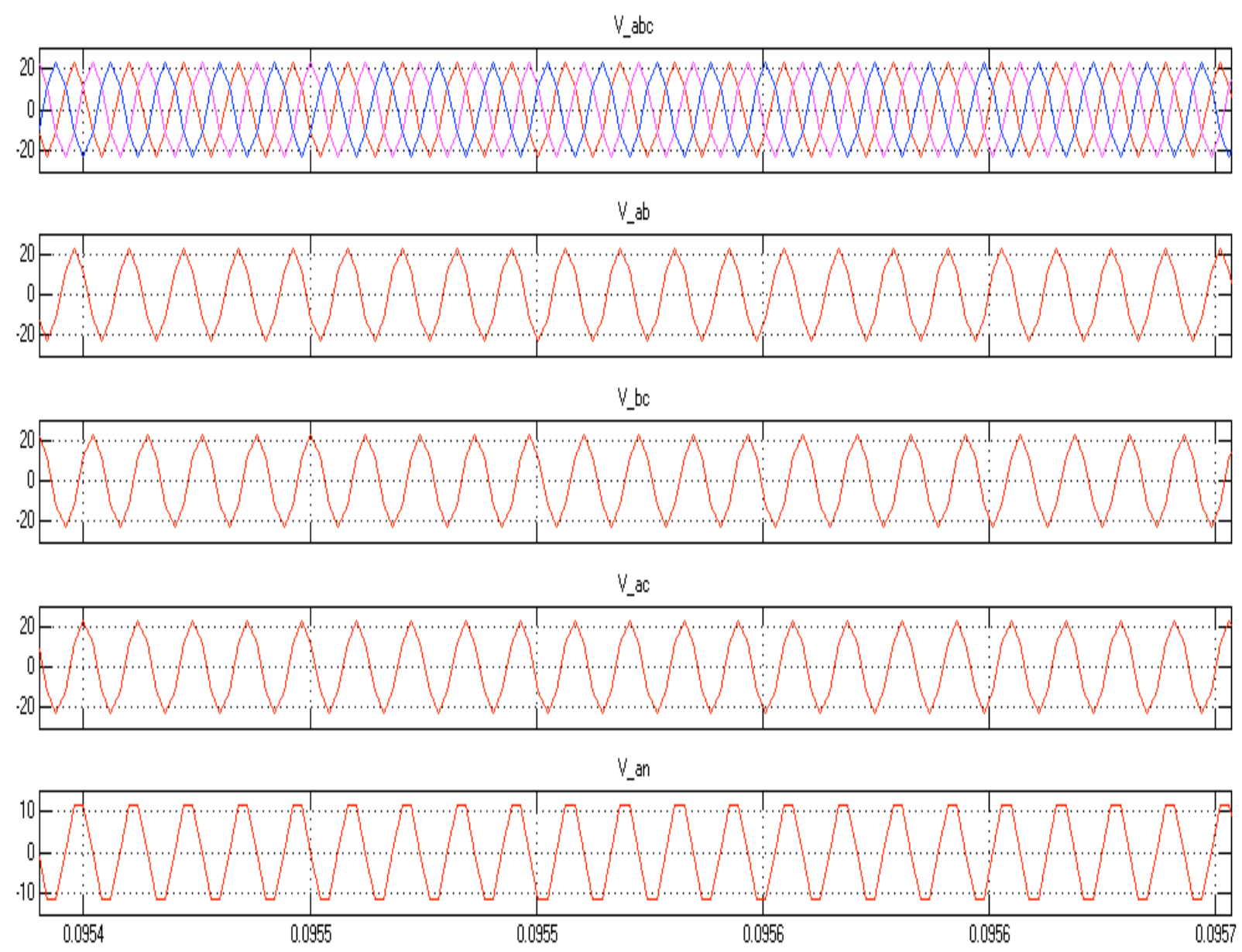

Figure 34: Output Induced voltage Waveforms

Figure shows the Induced phase and line voltage waveforms. Above plot shows that VAWT generated $12 \mathrm{~V}$ phase voltage and $21 \mathrm{~V}$ Line voltage. Top plot shows all 3-phase voltages, perfectly balanced at 120 degree from each other. 


\section{Rated Current}
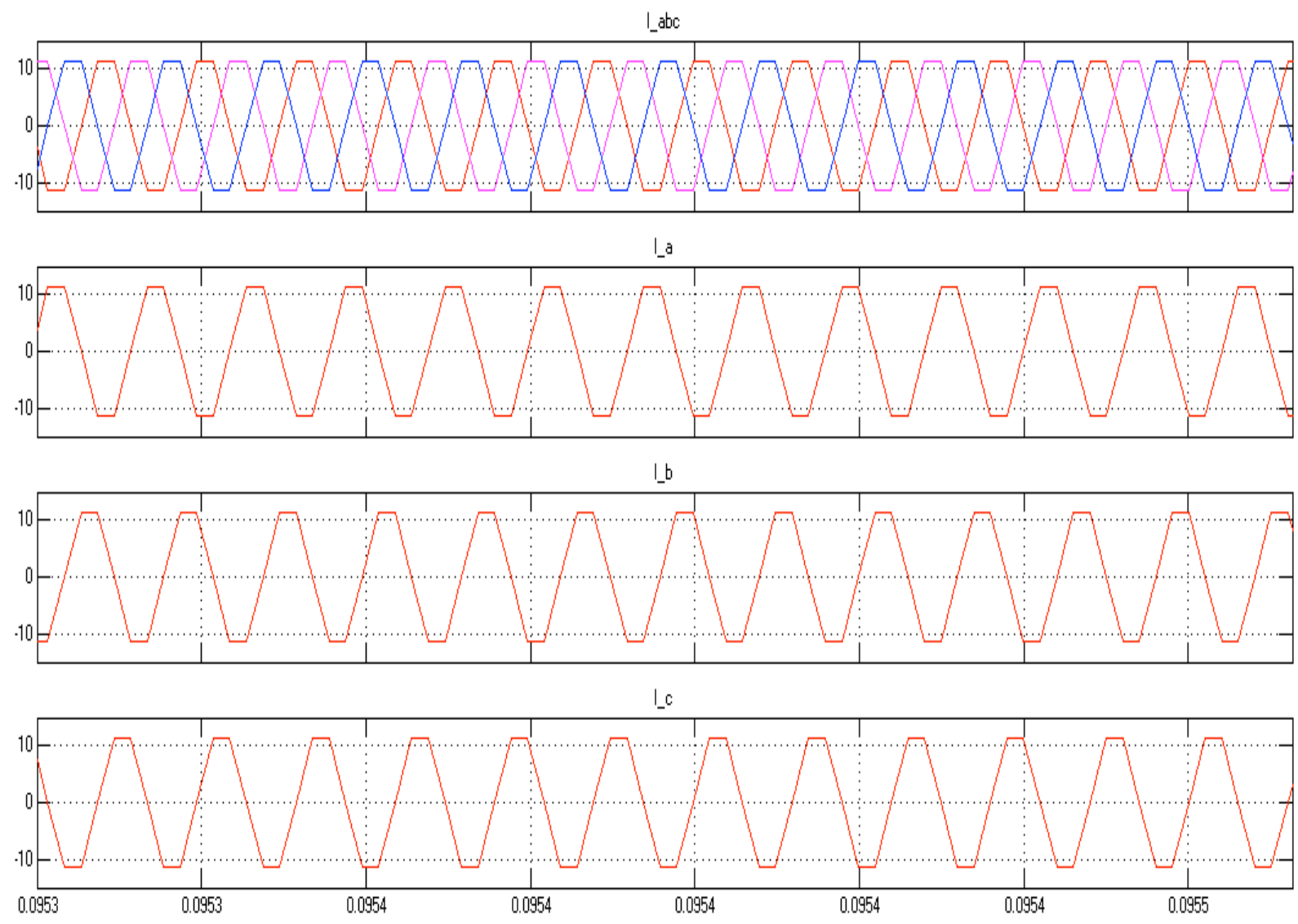

Figure 35: Rated Current Waveforms

Figure shows the rated current waveforms. Above plot shows that VAWT generated 10.3Amp rated current. Top plot shows all 3-phase currents, perfectly balanced at 120 degree from each other.

From both waveforms we can calculate total power generated by VAWT,

$$
\begin{gathered}
P=3 \times V_{\text {phase }} \times I \\
P=3 \times 12 \times 10.2=\mathbf{3 6 7 . 2} \mathbf{W}
\end{gathered}
$$




\section{CONCLUSION AND DISCUSSION}

The goal of this project is to design a Small Scale VAWT. These turbines are simple in construction and require less investment. The implementation of vertical axis wind turbine on road dividers, on side of train tracks and power supply for isolated area would be a great asset to the ministry of Non-conventional energy Resources as it would reduce the burden on the consumption of conventional energy sources. They can be installed on any highway with the width being the only constraint. Since, turbine size is small, it can harness a limited amount of wind. Therefore they can be used for street lighting on any busy road and light up the advertisement hoardings. Furthermore, these turbines can find application in lighting up commercial buildings. Other application could be in diversions on highways, traffic lights, industrial buildings, simply in household neighborhoods.

Since the battery is portable we can use it in some other location for any low voltage purpose. Thus there is balance between the cost and the power available. The emerging trends in the technology have shown a way to the use of non-conventional energy sources so efficiently and a little effort at the side may find an effective solution for the boom of the electrical energy by the society.

In order to properly design a generator there are many components that are required to be studied such as wind speed, power, current, voltage and many more. In order to calculate the important generator parameters, MATLAB script file was developed using all necessary equations. Additional constraints such as efficiency, copper and iron losses. This resulted in successful design calculations.

Successful calculation led me to implementation of this design. MATLAB Simulink software was used to make this VAWT simulation model. All the calculated values were implemented and observed the output. It was significant to modify a few values to improve 
output. Output voltage and current waveforms were analyzed and compared with calculated values.

Actual working model for VAWT was build up using these design parameters. A most important change to the design was to replace Ferrite magnets by neodymium magnets. Neodymium magnets are more cost efficient than Ferrite magnets, thus reducing overall cost. To achieve same magnetic field strength new design for magnet rotor disc was implemented and it was successful.

This model's total manufacturing cost was around $\$ 10,000+$ Cost of battery and inverter. Output phase voltage and current values were measured and compared with calculated and MATLAB simulation values.

Table 4 - Comparison table

\begin{tabular}{|c|c|c|c|}
\hline Parameters & Calculated Value & $\begin{array}{c}\text { MATLAB } \\
\text { Simulation }\end{array}$ & $\begin{array}{c}\text { Working VAWT } \\
\text { Model }\end{array}$ \\
\hline $\begin{array}{c}\text { Phase Voltage } \\
\text { (V) }\end{array}$ & 13.60 & 12 & 11.3 \\
\hline Line Voltage (V) & 23.56 & 21 & 20 \\
\hline Current (Amp) & 9.84 & 10.2 & 9.66 \\
\hline Power (W) & 368.19 & 367.2 & 327.47 \\
\hline Losses (W) & 33.355 & 30.8 & - \\
\hline Efficiency (\%) & 91.69 & 92.2 & 85 \\
\hline
\end{tabular}

Table shows the comparison of calculated value, MATLAB simulation output values and working VAWT model values for $7 \mathrm{~m} / \mathrm{s}$ wind speed. After observing these all values can conclude that this VAWT design is accurate. By implementing this model can save $\$ 8,465.76$ annually on electricity bills. 
Three phase PWM reversible rectifier topology is used to convert variable AC to regulated DC output. By use of this rectifier output at battery terminal will be constant $12 \mathrm{~V}$, even though wind speed and output voltage from generator varies in large scale. 


\section{REFERENCES}

- Yoon, Meej “Proposal forMicro Wind Turbine Installation” Presentation, Jan 28, 2010.

- Rathi Dhruv "Performance prediction and dynamic model of Vertical axis wind turbine blades with Aerodyunamically varied blade pitch," Masters of Science Thesis, June 2012

- T. Christopher, carper "Construction of vertical axis wind turbine using Dual-Layer Vacuum forming" Presented at Massachusetts institute of Technology, May19, 2010.

- K. Charilaos "Systems and knowledge Engineering Design of an Urban Vertical Axis Wind Turbine" Presentation for Masters of Science Thesis, January 2009.

- Cooper, P. and Kennedy, O. "Development and Analysis of a Novel Vertical Axis Wind Turbine" university of Wollongong, 2004

- Golding, E. and Harris, R. "The Generation of Electricity by Wind Power" E. \& F. Spon Ltd, London, 1976

- H. Polinder, J. A. Ferreira, B. B. Jensen, A. B. Abrahamsen, K. Atallah, and R. A. McMahon, “Trends in wind turbine generator systems," IEEE J. Emerg. Sel. Topics Power Electron., vol. 1, no. 3, pp. 174-185,Sep. 2013.

- Omijih,B.O., Nmom,C.S. and Nlewem,E. "Modeling of a Vertical Axis Wind Turbine with Permanent magnet synchronous Generator for Nigeria" Electrical/Electronic Engineering, University of Port Harcourt, Nigeria, February 2013

- Rolan,A., Alvaro L., Gerardo V., and Daniel A." Modelling of a Variable Speed Wind Turbine with a Permanent Magnet Synchronous Generator" 2009

- Wikipedia (2012): Wind Turbine History. Retrieved September 14, 2012, from http://en.wikipedia.org/wiki/Wind_turbine. 
- Bharanikumar R., Yazhini A.C., Kumar N. “Modelling and Simulation of Wind Turbine Driven Permanent Magnet Generator with New MPPT Algorithm" Asian Power electronics journal, Vol. 4, 2012

- Strunz Kai, Abbasi Ehsan and Huu Nguyen Due "DC Microgrid for Wind and Solar Integration" IEEE journal of Emerging and selected topics in Power Electronics" Vol-2, No.1, March 2014

- Dursun Erkan and Kilic Osman "Comparative evaluation of different power management strategies of standalone PV/Wind/PEMFC hybrid power system," Marmara university, Istanbul Turkey, 2011

- Jon Decoste, Denise Mckay, Brain Robinson, Shaun Whitehead and Stepen White "Vertical Axis Wind Turbine" Dalhousie University," December 2005

- Kanyako, Franklyn and Janajreh, Isam “Vertical Axis Wind Turbine Performance Prediction for Low Wind Speed Environment" Masdar Institute of science and technology, UAE

- “Global Wind Report Annual market update 2013”2013.

- R. Templin, “Aerodynamic performance theory for the vertical axis wind turbine" 1974.

- T. Wakui, Y. Tanzawa, T. Hashizume, and T. Nagao, "Hybrid configuration of Darrieus and Savonius rotors for stand-alone wind turbine-generator systems," Electrical Eng. Japan, vol. 150, no. 4, pp. 13-22, Mar. 2005.

- "Permanent Magnet Selection and Design Handbook" Advanced magnetic material manual from MAGCRAFT.

- M. H. Nehrir, C. Wang, K. Strunz, H. Aki, R. Ramakumar, J. Bing, et al., “A review of hybrid renewable/alternative energy systems for electric power generation: Configurations, control, and applications,” IEEE Trans. Sustain. Energy, vol. 2, no. 4, pp. 392-403, Oct. 2011.

- Schelbergen M., “ Structural Optimization of Multi-Megawatt, offshore Vertical Axis Wind Turbine Rotors" Masters of Science Thesis, Deft University of Technology, Nov-2013 
- R. Wilson, “Wind Turbine Aerodynamics,” Journal of Industrial Aerodynamics, no. 5, pp. 357$372,1980$.

- P. Musgrove, "Vertical Axis Wind Energy Conversion System Design," in Wind Energy Conversion Systems, L. Freris, Ed., Prentice Hall, 1990, pp. 295-306.

- W. Sanyer, “The Development of a Wind Turbine for Residential Use" Master's Thesis, North Carolina State University, 2011.

- I. S. Hwang, S. Y. Min, I. O. Jeong, Y. H. Lee and S. J. Kim, "Efficiency Improvement of a New ertical Axis Wind Turbine by Individual Active Control of Blade Motion," Smart Structures and Integrated Systems, Volume 6173, pp. 316-323, March 2006. 


\section{Appendix A}

\section{MATLAB CODE FOR VAAWT CALCULATIONS}

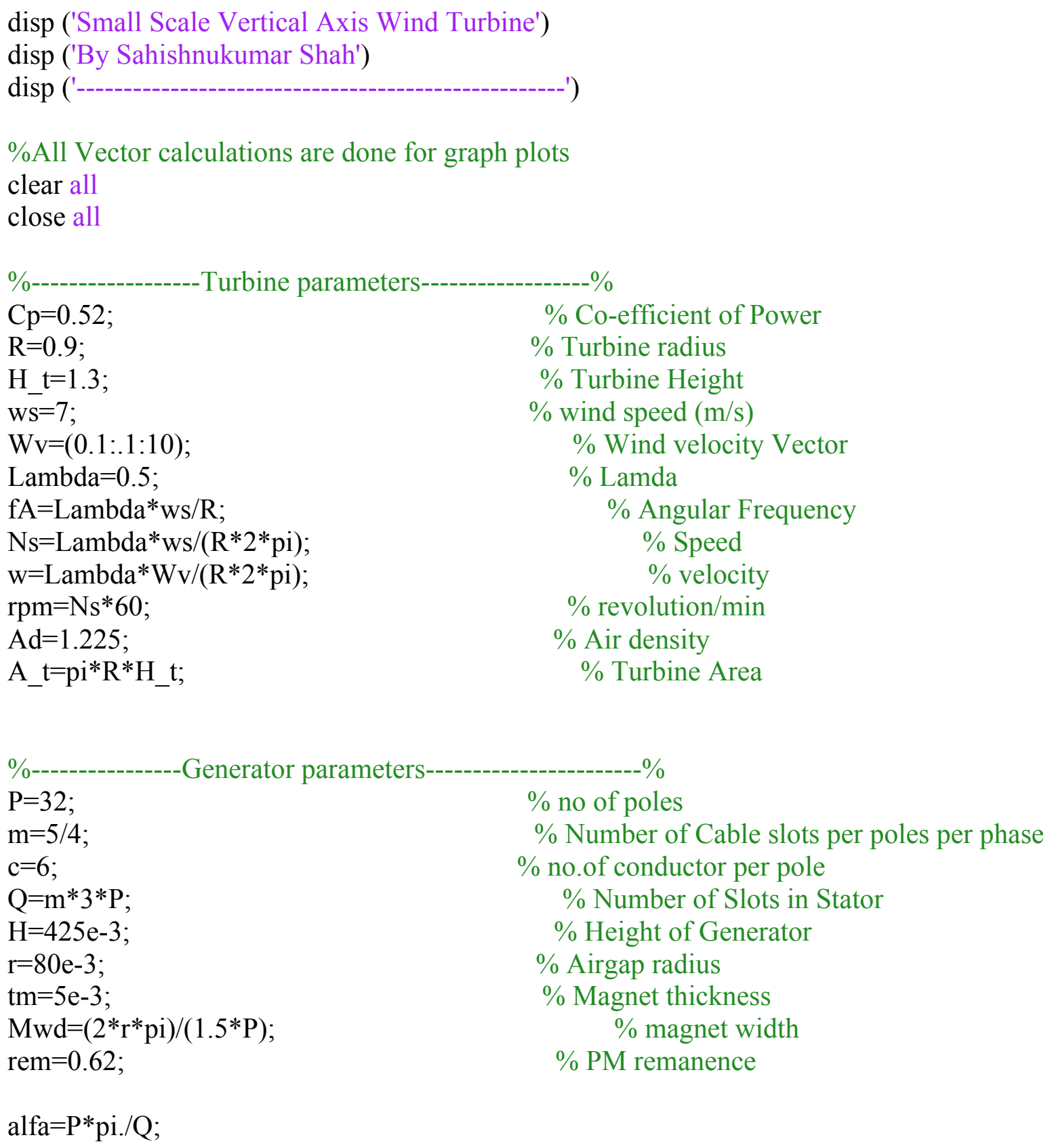


$\mathrm{f}=\mathrm{P} / 2 * \mathrm{Ns}$

f_vec $=\mathrm{P} / 2 * \mathrm{w}$;

$\mathrm{kp}=\operatorname{sind}(180 * \mathrm{P} * 3.5 /(2 * \mathrm{Q}))$;

$\mathrm{kd}=(\sin (\mathrm{m} \cdot *$ alfa $/ 2)) /\left(\mathrm{m} .{ }^{*} \sin (\mathrm{alfa} / 2)\right)$;

$\mathrm{kw}=\mathrm{kd} * \mathrm{kp}$;

$\mathrm{n}=(\mathrm{Q} . / 3){ }^{*} \mathrm{c} / 2$;

$\mathrm{CWd}=3.5 \mathrm{e}-3$;

$\mathrm{cc}=0.0015$;

A_cbl=pi* $\left((\mathrm{CWd} / 2)^{\wedge} 2\right)$;

$\overline{\mathrm{Mvl}}=\mathrm{Mwd} * \mathrm{H}^{*} \mathrm{tm} * \mathrm{P}$;

$\mathrm{Fi}=\mathrm{rem} .{ }^{*} \mathrm{H}^{*}{ }^{*} 4 / \mathrm{P}$

$\mathrm{Mwt}=\mathrm{Mvl}^{*} 1 \mathrm{e} 6 * 7.4$;

$\%$ Calculate Induced EMF

$\mathrm{ELN}=\operatorname{sqrt}(2) .{ }^{*} \mathrm{f} .{ }^{*}$ pi. ${ }^{*} \mathrm{kw} .{ }^{*} \mathrm{n} .{ }^{*} \mathrm{Fi}$;

$\mathrm{ELL}=\mathrm{ELN} .{ }^{*} \operatorname{sqrt}(3)$;

$\mathrm{EDC}=\mathrm{ELL} . * 1.35$;

$\%$ Generator geomatry calculations

Ytt_dia $=2 * r * 1.0641$;

$\mathrm{Ac}=(\mathrm{Q} * \mathrm{c} / 3) *(\mathrm{H}+\mathrm{cc} * 4 * \mathrm{pi} / 2)$;

$\%$ Power, Load and Current Calculations

Pgen $=0.5^{*} \mathrm{Ad}^{*} \mathrm{~A} \_\mathrm{t}^{*}\left(\mathrm{ws}^{\wedge} 3\right)^{*} \mathrm{Cp}$;

Load $=\left(\left(3^{*}\left(\mathrm{ELN}^{\wedge} 2\right)\right) /\right.$ Pgen $)$;

$\mathrm{I}=\mathrm{Pgen} /(3 * \mathrm{ELN})$;

$\%$ Losses

Rinn $=$ Ac*0.00104;

$\mathrm{Id}=\mathrm{I} /\left(\mathrm{A} \mathrm{cbl}{ }^{*} 1 \mathrm{e} 6\right)$;

$\mathrm{Bmax}=1.68$;

$\mathrm{kc}=9.77 \mathrm{e}-05$;

P_cu $=3 *$ Rinn $* I^{\wedge} 2$;

$\mathrm{P} \_$ir $=\left(\mathrm{Kh}^{*} \mathrm{Bmax}^{\wedge} 2 * \mathrm{f}+\mathrm{Kc}^{*} \mathrm{Bmax}^{\wedge} 2 * \mathrm{f}^{\wedge} 2+\mathrm{Ke}^{*} \mathrm{Bmax}^{\wedge} 1.5 * \mathrm{f}^{\wedge} 1.5\right) * \mathrm{Swt}$;

$\mathrm{L}$ total $=\mathrm{P}$ ir $+\mathrm{P}$ ccu;

$\mathrm{Pt}=$ Pgen $-\mathrm{L}$ total;

$\mathrm{eff}=(\mathrm{Pt}) /(\mathrm{Pt}+\overline{\mathrm{L}}$ total $)$;

$\%$ Vector calculations for plots

ELN_vec=sqrt(2).*pi.*f_vec. ${ }^{*}$ kr. ${ }^{*}$ n. ${ }^{*} \mathrm{Fi}$;

ELL_vec $=$ ELN_vec.* ${ }^{*} \operatorname{sqrt}(3)$;

$\%$ Frequency

$\%$ Pitch factor

$\%$ Winding Factor

$\%$ Cable width

$\%$ Cable area

$\%$ Magnet volume

$\%$ Magnetic flux

$\%$ Magnet weight

$\%$ Power

$\%$ Current

$\%$ inner resistant

$\%$ Current density - J

$\%$ Copper Losses
$\left.1.5^{*} f^{\wedge} 1.5\right)^{*}$ Swt;

$\%$ DC voltage

$\%$ Frequency vector or frequency in $\mathrm{rad} / \mathrm{s}$

$\%$ Distribution factor

$\%$ Coil's number of turns per phase (winding)

$\%$ Cable cross section area

$\%$ maximum magnetic flux density

$\%$ Induced Line Voltage

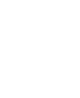




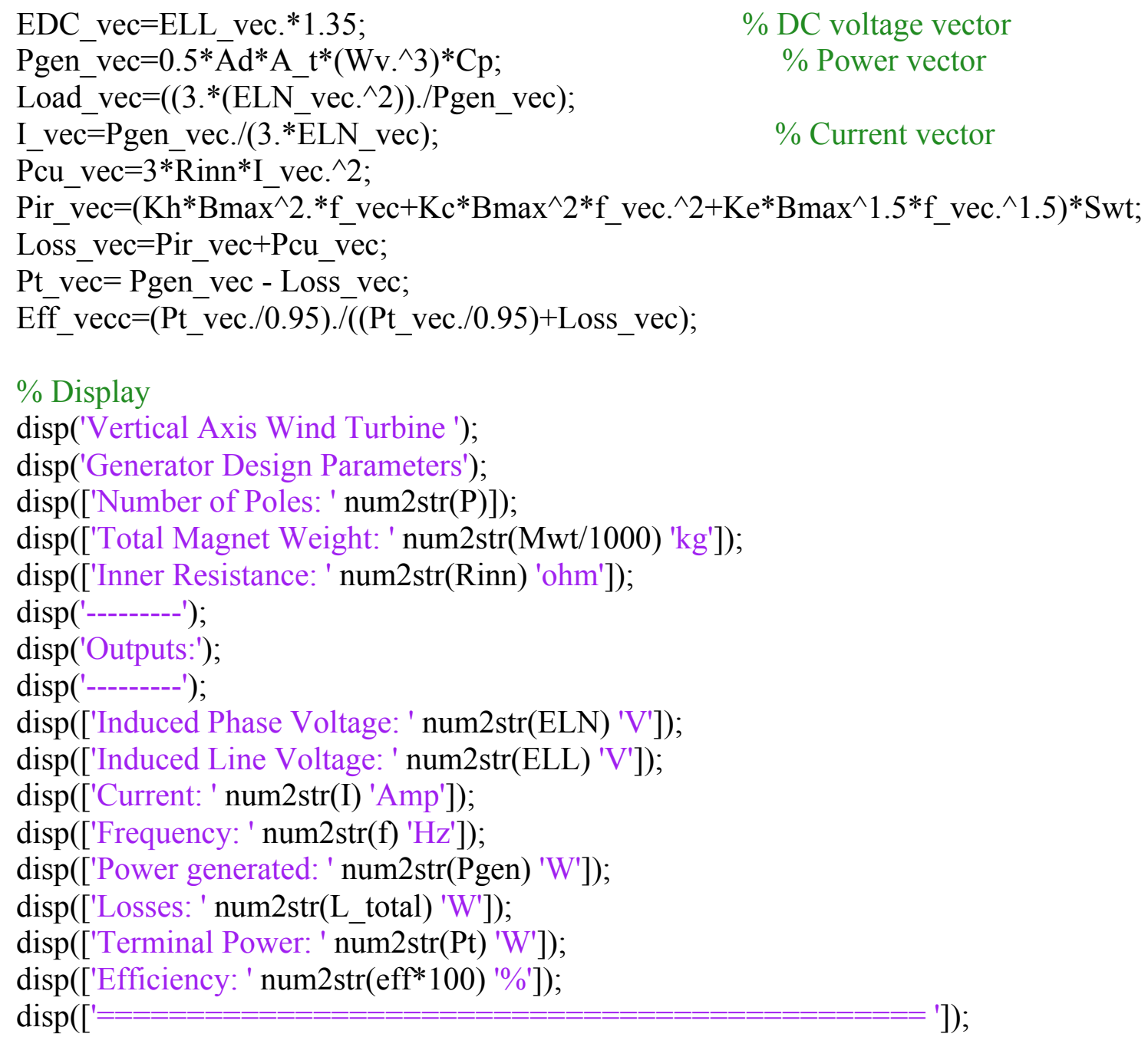




\section{Appendix B - MATLAB Simulation Model}

MATLAB simulation Model for VAWT.

\begin{tabular}{l} 
Continuous \\
\hline powergui
\end{tabular}
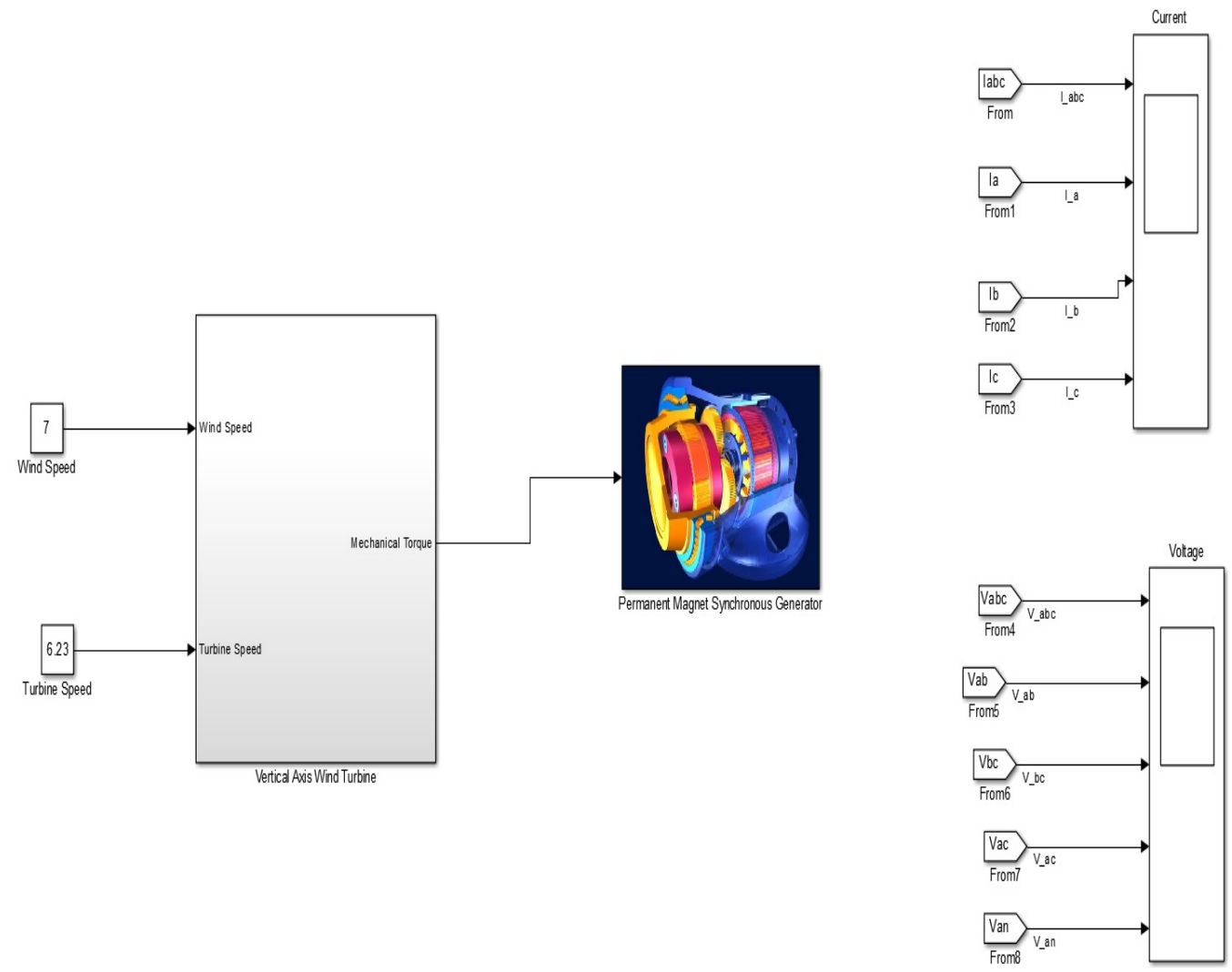